\title{
Optimal configuration, design and control of a binary geothermal combined heat-and-power plant
}

Sarah Van Erdeweghe, Johan Van Bael and William D'haeseleer

TME WORKING PAPER - Energy and Environment Last update: July 2019

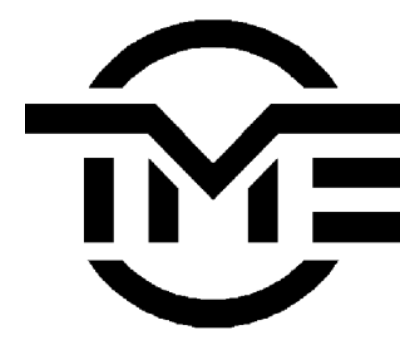

An electronic version of the paper may be downloaded from the TME website: http://www.mech.kuleuven.be/tme/research/ 


\title{
Optimal configuration, design and control of a binary geothermal combined heat-and-power plant
}

\author{
Sarah Van Erdeweghe ${ }^{\mathrm{a}, \mathrm{c}}$, Johan Van Bael $^{\mathrm{b}, \mathrm{c}}$, William D'haeseleer ${ }^{\mathrm{a}, \mathrm{c}, *}$ \\ ${ }^{a}$ University of Leuven (KU Leuven), Applied Mechanics and Energy Conversion Section, Celestijnenlaan 300 - box \\ 2421, B-3001 Leuven, Belgium \\ ${ }^{b}$ Flemish Institute for Technological Research (VITO), Boeretang 200, B-2400 Mol, Belgium \\ ${ }^{c}$ Energy Ville, Thor Park 8310, B-3600 Genk, Belgium
}

\begin{abstract}
In this paper, a two-step design optimization framework is developed for four low-temperature geothermal combined heat-and-power plant configurations. The economic comparison, including off-design performance, has not been done before. The optimization tool is applied for an existing district heating system and for geothermal and meteorological conditions which are based on the Belgian situation. It is concluded that a combined heat-and-power plant results in an economically profitable project (net present value of 3.46MEUR), whereas the stand-alone electrical power plant does not (net present value of -3.65MEUR). Furthermore, the design for the series set-up is optimal, and the best connections during operation are the series and parallel connections for low and high heat demands, respectively. Also, a less detailed (high-level) control optimization model is developed for this series set-up, based on the part-load operating maps which are calculated from the detailed two-step optimization model results. The calculation time is much faster $(\sim$ milliseconds $)$ and the errors on the total revenues are smaller than $0.1 \%$. The goal of this high-level model is to optimize the amounts of heat and electricity to produce, so that the plant can be used as a flexibility tool in energy markets driven by price signals for heat and electricity.
\end{abstract}

Keywords: design optimization, CHP, geothermal energy, off-design performance, ORC, thermoeconomics

\footnotetext{
* Corresponding author

Email address: william.dhaeseleer@kuleuven.be (William D'haeseleer)
} 


\section{Introduction}

There is large potential for geothermal energy utilization around the world. However for nonvolcanic regions, like NW Europe, stand-alone electrical power production from deep-geothermal energy sources is mostly not economically attractive due to the high drilling costs (caused by low geothermal gradients) and the low production temperatures [1]. Therefore, the potential for geothermal combined heat-and-power (CHP) plants in NW Europe will be investigated in this study. The idea is to improve the economics of a geothermal plant by getting revenues from selling heat next to electricity.

\subsection{Existing literature}

Geothermal CHP plants have already been studied in the literature . Heberle et al. [2] have studied the series and parallel connections of heat and electricity production via an organic Rankine cycle (ORC) based on a second law analysis. Different values for the geothermal source temperature (90$\left.180^{\circ} \mathrm{C}\right)$, the supply temperature of the heating system $\left(60-90^{\circ} \mathrm{C}\right)$ and heat demands $(3.5-10.5 \mathrm{MWth})$ were assumed. The authors concluded that a CHP plant has higher efficiency than electrical power production only, and that the series configuration is the most efficient concept for the investigated conditions. However the authors did not consider off-design operation; they indicated that the parallel circuit has some technical advantages regarding part-load behavior of the ORC. Habka et al. [3] have studied the series, the parallel and the so-called Glewe and four additional configurations (called HB1 to HB4) for a geothermal CHP plant. The heat source considered had a temperature of $100^{\circ} \mathrm{C}$ and a flow rate of $1 \mathrm{~kg} / \mathrm{s}$. Supply and return temperatures of the district heating system around $75^{\circ} \mathrm{C}$ and $50^{\circ} \mathrm{C}$ and a heat production of $110-170 \mathrm{~kW}$ were considered. They concluded that a higher heat demand leads to lower electricity production but better energy source utilization, that the electrical power output of the parallel set-up is not affected by the heating system supply temperature and that the Glewe set-up does not give better performance than the series configuration. Furthermore, the authors indicated the HB4 set-up as a potential state-of-the-art CHP plant configuration for low-temperature geothermal energy sources. A high electricity production can be reached (up to $88 \%$ of the stand-alone electrical power plant), and the set-up is still relatively simple. However, the results were based on thermodynamics, so neither economics nor off-design behavior were included. 
Also different CHP configurations have been studied for higher source temperatures . Fiaschi et al. [4] have investigated the so-called Cross-Parallel CHP set-up for medium-temperature geothermal energy sources $\left(130-170^{\circ} \mathrm{C}\right)$. Industrial heat production (with temperatures of $80-140^{\circ} \mathrm{C}$ ) was targeted and the net electrical power output was maximized for a given heat demand. For the considered conditions, the Cross-Parallel set-up shows up to $55 \%$ higher net electrical power output than the normal parallel configuration. The authors suggested to use this CHP configuration in regions where district heating is not needed and where industrial heat (at higher temperatures) could be used. Wieland et al. [5] have proposed a novel CHP configuration and they have compared it with the conventional series, parallel and condensation concepts (and their combinations) in terms of flexibility and energy source utilization. The novel CHP set-up is a two-stage recuperated ORC where heat of turbine bleeding is fed to a district heating (DH) system. Source temperatures of $240^{\circ} \mathrm{C}$ and $340^{\circ} \mathrm{C}$ were considered which represent internal combustion engine waste heat and biomass, respectively. The DH system supply and return temperatures were $80^{\circ} \mathrm{C}$ and $50^{\circ} \mathrm{C}$, respectively. The authors concluded that the proposed novel configuration is flexible, has a large cover ratio and has high electrical efficiency for the considered source temperatures. However, the off-design performance was based on fixed UA-values of the heat exchangers, which is a strong assumption. Oyewunmi et al. [6] have studied different working fluid mixtures for application in an ORC in which the condenser heat is used for heat purposes (with supply temperatures of $30-90^{\circ} \mathrm{C}$ ). Industrial waste heat was considered with temperatures of $150-330^{\circ} \mathrm{C}$. Based on thermodynamic optimization results, they found that single-component working fluids are optimal for lower-temperature heat demands and that the best exergy efficiency of $63 \%$ is achieved for the heat source temperature of $330^{\circ} \mathrm{C}$, delivering water at $90^{\circ} \mathrm{C}$ and adopting a mixture of $70 \%$ n-octane and $30 \%$ n-pentane as a working fluid. Besides, the authors concluded that electricity and heat exergy production are competing objectives.

The aforementioned studies are purely thermodynamic and do not include cost estimations. However, the results for a thermodynamic and a thermoeconomic optimization are significantly different [7], and investors' decisions are based on economics rather than thermodynamics. Furthermore, it is very important to account for off-design performance. As shown by Usman et al. [8], the environment conditions have significant effect on the power output of a geothermal plant. They designed a geothermal power plant for four different locations and they compared the use of a wet cooling tower with an air-cooled condenser. The design of the cycle was based on the maximal electrical 
power production in summer time. Furthermore, the cooling system was controlled during operation in order to get the highest electricity production for varying environment conditions. The authors designed the components in such a way that the ORC could benefit from higher pressure ratios (hence higher electrical power production) in winter, without over-sizing the system. They recommend a wet cooling tower for hot climates and a dry-cooling system for mild climates (like NW Europe). Also Hu et al. [9] have made an off-design analysis of a geothermal ORC, with a source temperature and flow rate of $90^{\circ} \mathrm{C}$ and $10 \mathrm{~kg} / \mathrm{s}$. Those authors optimized the thermodynamic cycle towards maximal net electrical power production, and the turbine and heat exchangers were designed based on the optimal thermodynamic conditions. During off-design, the geothermal fluid mass flow rate, evaporator pressure and coolant flow rate were controlled. Furthermore, Astolfi et al. [10] have made an off-design thermoeconomic optimization for a low-temperature geothermal ORC $\left(120^{\circ} \mathrm{C}, 120 \mathrm{~kg} / \mathrm{s}\right)$ in desert climate and for high electricity prices. They studied the novel LU-VE Emeritus cooling system which is a dry cooling system with water sprays and adiabatic panels, and they optimized the condenser temperature and the number of cooling modules. They compared the novel system with a standard dry-cooler and concluded that for environment temperatures from $15-37^{\circ} \mathrm{C}$, the use of adiabatic panels leads to lower condenser temperatures, higher electricity productions, lower auxiliary power consumption by the fans and higher cash flows but also higher costs for water consumption. For environment temperatures above $37^{\circ} \mathrm{C}$, the water spray system enhances the benefits even more (a threshold of 500 hours of spray operation mode was assumed). Below $15^{\circ} \mathrm{C}$, the water costs are higher than the incomes from selling more electricity and the dry-cooler performs better. Part-load operation might also be caused by geothermal heat source degradation. Budisulistyo et al. [11] have considered the design of a geothermal power plant in New Zealand, taking into account the heat source degradation over its lifetime (starting from $131^{\circ} \mathrm{C}$ and $200 \mathrm{~kg} / \mathrm{s}$ ). They performed a design optimization towards maximal electricity production for the heat source at years 1, 7, 15 and 30 of operation. Then, the performance during the entire plant's lifetime was simulated. The NPV is the highest for the design based on the energy source conditions of year 7 .

Furthermore, two works have suggested a two-step optimization where off-design operation is already considered in the design stage. Lecompte et al. [12] have studied an ORC fed by waste heat from an internal combustion engine. First, the ORC was designed for different combinations of heat content of the heat source and environment temperature values. The specific investment cost (SIC) 
was considered as the optimization objective. Then, the off-design optimization was done for every ORC design towards maximal electricity production, based on hourly data. The part-load operation was caused by the fluctuating heat source and varying environment conditions. Finally, the real SIC including off-design behavior was calculated and the best design parameters for the heat source heat content and the environment temperature could be defined. Those authors concluded that the SIC value with and without taking part-load operation into account can differ significantly, up to 26\%. Martelli, Capra and Consonni [13] have studied a biomass-fired CHP plant in which the ORC condenser heat is used to satisfy the heat demand. In the first step, the cycle conditions, heat transfer areas and turbine design variables were optimized towards maximum annual profits. Then, the part-load operation was optimized and the real annual profits were calculated. This info was returned back to the design solver. Those authors concluded that taking the off-design behavior into account in the design stage may lead to $22 \%$ higher annual profits, and that the optimal ORC is slightly undersized.

\subsection{Contribution of this work}

In this work, a similar two-step optimization framework is developed for the optimal design of four CHP plant configurations fueled by low-temperature geothermal energy in NW Europe. The proposed two-step thermoeconomic optimization framework allows finding the best suited binary geothermal CHP plant design, taking into account the optimal configuration during operation (which might be a CHP configuration which is different from the configuration for which the CHP plant was designed) and its off-design performance. Heat is delivered to a DH system and electricity is produced via an ORC. Figure 1 gives a schematic outline of the four investigated CHP configurations: the series $(\mathrm{S})$, the parallel $(\mathrm{P})$, the preheat-parallel (PP) [14] and the HB4 [3] set-up.

The CHP configurations have already been thermodynamically investigated in [15], and the optimal design has been calculated for several types of heat demands in [14]. However, always a fixed heat demand and fixed operating conditions were considered. In this work, the off-design optimization models are developed and the optimal CHP design will be indicated for the connection to a DH system with a strongly fluctuating heat demand (and varying operating temperatures) and accounting for the varying environment conditions. The part-load performance as well as a change of connections during off-design are considered, which is novel compared to the existing 


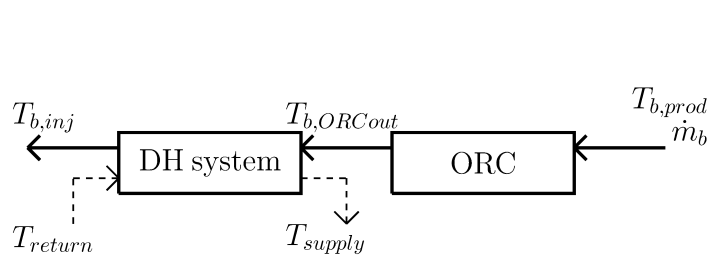

(a) Series (S)

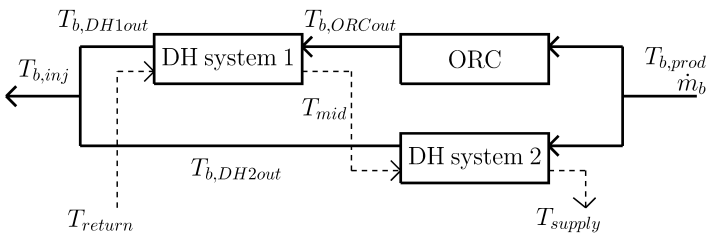

(c) Preheat-parallel (PP)

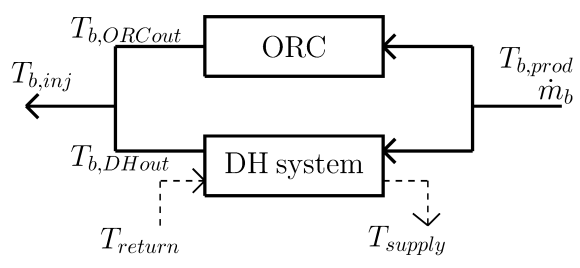

(b) Parallel (P)

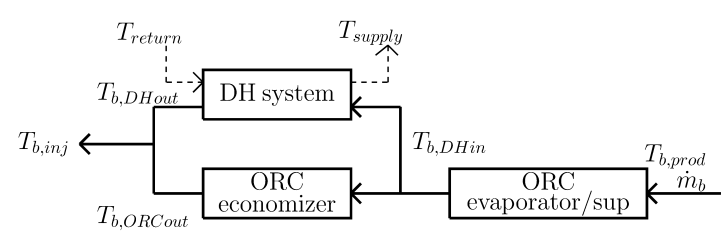

(d) HB4

Figure 1: CHP plant configurations with indication of the nomenclature [3, 14]. The full lines indicate the path of the brine (geothermal water) and the dashed lines indicated the path of the district heating system water.

literature.

Additional novelties are that detailed thermodynamic correlations are used for the heat transfer coefficient and friction factor calculations, also in the off-design models. This is in contrast to fixed pressure drop and fixed UA assumptions for the heat exchangers, or simplified correlations based on a power law of the mass flow rate ratio. Furthermore, hourly data for the environment conditions and for the heat profile are used, which are more accurate than monthly-averaged or constant values. And finally, up to the authors' knowledge, none of the papers in which the design optimization of a CHP plant is discussed also considers real (hourly) off-design control. This is probably because the used models are too detailed and too slow $(\sim$ minutes/hours $)$ to be able to do this control optimization in a reasonable amount of time. Therefore, in this work, an additional high-level optimization model is developed based on part-load operation maps which are derived from the detailed thermoeconomic optimization results. This high-level control model is able to calculate the optimal amount of electricity and heat production of a certain CHP plant depending on the price signals for heat and electricity. It is very fast $(\sim$ milliseconds $)$ and can be used for real-time control of an installed CHP plant. 


\section{Methods}

\footnotetext{
${ }^{1}$ The T-s diagrams result from the thermoeconomic design optimization tool for a standard and a recuperated stand-alone electrical power plant.
} 

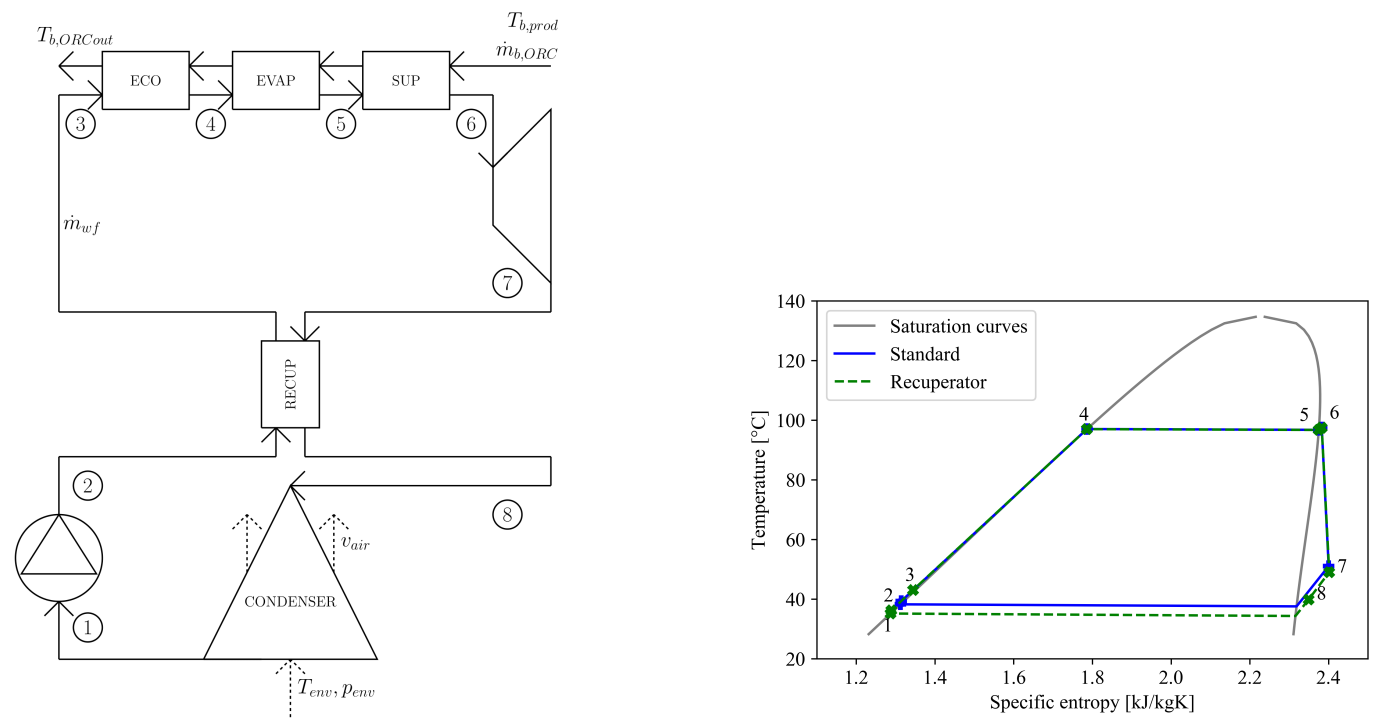

Figure 2: Left: Schematic outline of the recuperated organic Rankine cycle (ORC). Right: T-s diagram for the standard (blue full lines) and the recuperated ORC (green dashed lines).

economic conditions comprise the electricity price $\left(p_{e l}\right)[17]$ and the yearly electricity price increase $\left(d_{e l}\right)[18]$, the heat price $\left(p_{\text {heat }}\right)$ [19], the discount rate $(d r)[20]$, the lifetime $(L)$ and the availability $(N)$ of the plant [21]. Besides, some assumptions are made regarding the thermodynamic cycle: for the isentropic pump efficiency $\left(\eta_{p}\right)$ [22], the generator and motor mechanical-to-electrical efficiencies $\left(\eta_{g}\right.$ and $\left.\eta_{m}\right)$ [23], the fan efficiency $\left(\eta_{f}\right)$ [24], the minimum temperature difference over the heat exchangers $\left(\Delta T_{\min }\right)$ and the minimum degree of superheating $\left(\Delta T_{\text {sup }}^{\min }\right)$. Although $\Delta T_{\min }=1^{\circ} \mathrm{C}$ in the design model (superscript $D), \Delta T_{\min }=0.75^{\circ} \mathrm{C}$ in the off-design model (superscript $O$ ) to allow proper cycle convergence. The environment conditions and DH system parameters have been measured on-site [25]. On the left-hand side of Figure 3, the environment temperature (black dashdotted line) and the heat demand (red line) are shown. The available data start on January 1st 20167 o'clock and run until January 1st 20176 o'clock. The design of the CHP plants is based on the average value for the heat demand $\left(\dot{Q}_{D H}^{a v}\right)$ and the average environment conditions (temperature $T_{e n v}^{a v}$ and pressure $\left.p_{e n v}^{a v}\right)$. The corresponding supply and return temperatures $\left(T_{\text {supply }}\right.$ and $\left.T_{\text {return }}\right)$ are considered, which are linearly dependent on the environment temperature. The dependencies for $T_{\text {supply }}$ (red full line) and $T_{\text {return }}$ (blue dashed line) are shown on the right-hand side of Figure 3. The pressure of the water in the DH system $\left(p_{D H}\right)$ depends on the length and height differences, 


\begin{tabular}{c|c|c|c|c} 
Brine \& wells [16] & Economic $[17-21]$ & Cycle $[22-24]$ & Environment $[25]$ & DH system [25] \\
\hline$T_{b, \text { prod }}=130^{\circ} \mathrm{C}$ & $p_{\text {el }}=60 \mathrm{EUR} / \mathrm{MWh}$ & $\eta_{p}=80 \%$ & $T_{\text {env }}^{a v}=12.15^{\circ} \mathrm{C}$ & $\dot{Q}_{D H}^{a v}=2.76 \mathrm{MWth}$ \\
$p_{b, \text { prod }}=40 \mathrm{bar}$ & $d_{\text {el }}=1.25 \% /$ year & $\eta_{g}=98 \%$ & $p_{\text {env }}^{a v}=1.01 \mathrm{bar}$ & $T_{\text {supply }}=70.61^{\circ} \mathrm{C}$ \\
$\dot{m}_{b}=150 \mathrm{~kg} / \mathrm{s}$ & $p_{\text {heat }}=25 \mathrm{EUR} / \mathrm{MWh}$ & $\eta_{m}=98 \%$ & & $T_{\text {return }}=63.74^{\circ} \mathrm{C}$ \\
$I_{\text {wells }}=15 \mathrm{MEUR}$ & $d r=5 \%$ & $\eta_{f}=60 \%^{2}$ & & $p_{D H}^{a v}=7 b a r$ \\
$\dot{P}_{\text {wells }}=500 \mathrm{kWe}$ & $L=30 y e a r s$ & $\Delta T_{\text {min }}^{D}=1^{\circ} \mathrm{C}$ & & \\
& $N=90 \%$ & $\Delta T_{\min }^{O}=0.75^{\circ} \mathrm{C}$ & & \\
& & $\Delta T_{\text {sup }}^{\min }=1^{\circ} \mathrm{C}$ & &
\end{tabular}

Table 1: Reference parameter values [16-25].
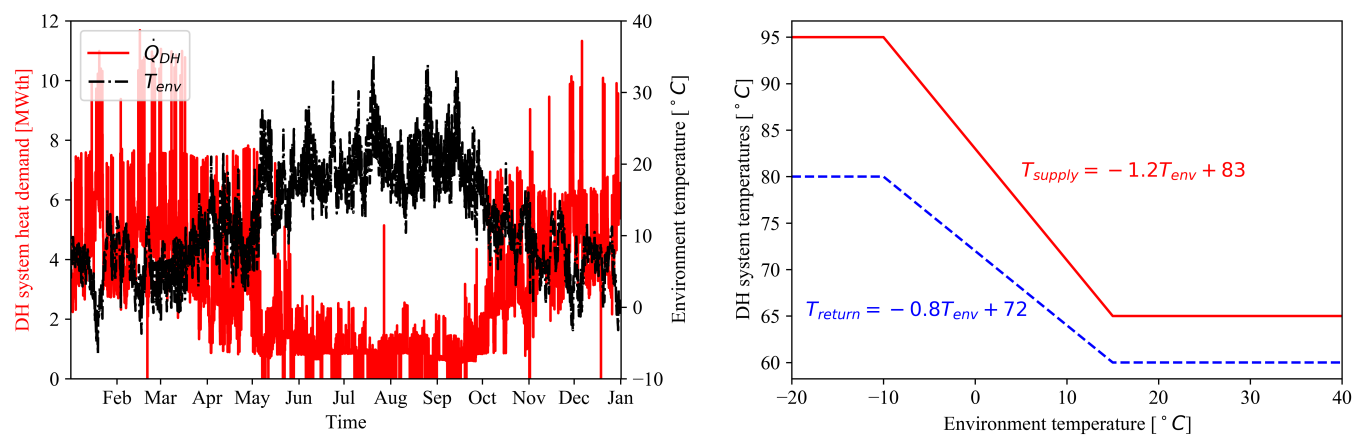

Figure 3: Left: District heating system heat demand $\left(\dot{Q}_{D H}\right.$, red full line) and environment temperature $\left(T_{e n v}\right.$, black dashdotted line) for the representative year [25]. Right: Supply ( $T_{\text {supply }}$, red full line) and return ( $T_{\text {return }}$, blue dashed line) temperatures of the district heating system as a function of the environment temperature. 
$N P V=-I_{\text {wells }}-I_{O R C}-I_{D H}+\sum_{i=0}^{L-1} \frac{\left(\dot{P}_{n e t} p_{e l}\left(1+d_{e l}\right)^{i}+\dot{Q}_{C H P} p_{\text {heat }}\right) N 8760-0.025\left(I_{O R C}+I_{D H}\right)}{(1+d r)^{i}}$

$$
L C O E=\frac{I_{\text {wells }}+I_{O R C}+I_{D H}+\sum_{i=0}^{L-1} \frac{\left[0.025\left(I_{O R C}+I_{D H}\right)-\dot{Q}_{C H P} p_{h e a t} 8760 N\right]}{(1+d r)^{i}}}{\sum_{i=0}^{L-1} \frac{\dot{P}_{n e t}\left(1+d_{e l}\right)^{i} 8760 N}{(1+d r)^{i}}}
$$

ozone depletion potential $(O D P)$, the global warming potential over a time horizon of 100 years

\begin{tabular}{c|c|c|c|c|c|c} 
& $M W[\mathrm{~g} /$ mole $]$ & $T_{\text {crit }}\left[{ }^{\circ} \mathrm{C}\right]$ & $p_{\text {crit }}[\mathrm{MPa}]$ & $O D P$ & $G W P_{100}$ & atm. life [years] \\
\hline R600a & 58.12 & 134.7 & 3.63 & 0 & 20 & 0.02
\end{tabular}

Table 2: Thermodynamic and environmental properties of isobutane (R600a) [27].

\subsection{Performance indicators}

The net present value (NPV) is the most important economic performance indicator and is defined as:

Herein, a yearly maintenance cost of $2.5 \%$ of the equipment investment costs is assumed [29]. $I_{O R C}$ and $I_{D H}$ are the overnight installation costs for the ORC and the DH system heat exchanger(s), respectively. $\dot{P}_{n e t}$ and $\dot{Q}_{C H P}$ are the net electrical power output and the heat production of the CHP plant.

Also the levelized cost of electricity (LCOE) is considered as an economic metric and is defined as:

In this definition, the revenues from selling heat are included.

Next to the economic performance indicators, also some thermodynamic indicators are included. The net electrical power output is the electrical turbine power minus the ORC pump power, the fan power of the cooling system and the well pumps power:

$$
\dot{P}_{n e t}=\dot{P}_{t}-\dot{P}_{p}-\dot{P}_{f}-\dot{P}_{w e l l s}
$$

In the considered convention, all powers are positive. The electrical turbine and pump powers are:

$$
\dot{P}_{t}=\dot{m}_{w f} w_{t} \eta_{g} \text { and } \dot{P}_{p}=\frac{\dot{m}_{w f} w_{p}}{\eta_{m}}
$$


with $\dot{m}_{w f}$ the working fluid mass flow rate, $w_{t}=h_{6}-h_{7}$ and $w_{p}=h_{2}-h_{1}$. The electrical fan power is:

$$
\dot{P}_{f}=\frac{\dot{V}_{a i r} \Delta p_{a i r}}{\eta_{f}}
$$

with $\dot{V}_{a i r}$ the air volume flow rate and $\Delta p_{\text {air }}$ the air pressure drop.

The specific work is a property of the ORC, and is based on the mechanical work of the ORC turbine and pump:

$$
w=w_{t}-w_{p}
$$

The ORC cycle energy efficiency is defined as:

$$
\eta_{e n}=\frac{w_{t}-w_{p}}{q_{E E S}}
$$

with $q_{E E S}$ the specific heat added to the ORC. And finally, the exergetic plant efficiency is the ratio of the flow exergy content of the produced electricity and heat (accounting for the amount of energy and its usefulness/temperature level) and the total exergy content of the brine at the production state:

$$
\eta_{e x}=\frac{\dot{P}_{n e t}+\dot{E} x_{D H}}{\dot{m}_{b} e x_{b, p r o d}}
$$

The specific exergy ex $=\left(h-h_{e n v}\right)-T_{\text {env }}\left(s-s_{\text {env }}\right)$ is a state property. In this definition of $\eta_{e x}$, the flow exergy which is still available at the injection state of the brine is considered as a loss.

\subsection{Detailed thermoeconomic optimization framework}

The detailed thermoeconomic optimization framework for the CHP plants is based on the twostep optimization framework which has already been developed by the authors for a stand-alone electrical power plant [7]. However, the framework has been extended for heat delivery and off-design modeling (caused by fluctuating heat demand/temperatures and varying environment conditions) for the four investigated CHP types. All optimization models are implemented in Python [30], and the CasADi optimization framework [31] with IpOpt non-linear solver [32] is used. Fluid properties are called from the REFPROP 8.0 database [33]. 


\subsubsection{Components and thermoeconomic models}

TEMA E shell-and-tube heat exchangers are considered with the brine flowing in the tubes or the liquid working fluid in the tubes for the recuperator. The economizer, evaporator and superheater of Figure 2 (called EES further on) are considered to have the same geometry, which eases offdesign operation. Furthermore, a multi-stage centrifugal pump, a single-stage axial turbine and an A-framed air-cooled condenser (called $A C C$ further on) with corrugated fins are assumed. Aircooling is considered since no cooling water has to be available and since it is the approprate cooling system in mild climates (like NW Europe) [8]. The same models for the geometrical, heat transfer, pressure drop and turbine efficiency calculations are used as in [7].

The bare equipment cost method is used for the cost calculations. Correction factors for high temperatures $\left(>100^{\circ} \mathrm{C}\right)$, high pressures $(>7$ bar $)$ and the need for stainless steel in the heat exchangers: $f_{T}=1.6, f_{p}=1.5$ and $f_{M}=1.7$ are considered [34]. Furthermore, an installation factor of $f_{I}=0.6$ is assumed [35]. The equipment cost $C$ thus becomes:

$$
C=C_{B E}\left(f_{T} f_{p} f_{M}+f_{I}\right)
$$

with $C_{B E}$ the bare equipment cost which is based on the heat transfer area. For the turbine, the pumps and fans, the bare equipment cost is based on the power. The costs are converted to 2016based values via the chemical engineering index and a conversion factor of $E U R-t o-U S D=1.2$ is assumed.

\subsubsection{Design optimization model}

In the first step of the detailed two-step thermoeconomic optimization framework, the geometry of the heat exchangers (shell inner diameter $D_{\text {shell }}$, tube outer diameter $D_{\text {tube }}$, tube pitch $p_{\text {tube }}$, baffle cut length $B_{c}$ and length between the baffles $L_{b c}$ ) and of the air-cooled condenser (fin spacing $S_{f i n}$, fin height $H_{\text {fin }}$ and number of tubes $n_{\text {tube }}$ ) are optimized together with the operating conditions in the design point. The NPV is considered as the objective. Note that up to four heat exchangers (EES, RECUP, DH system and DH system 2) might be present, depending on the configuration (see Figure 1). The design optimization model has been proposed in a previous paper by the authors $[14]$. 


\subsubsection{Off-design optimization model}

The actual performance during operation is calculated for the CHP plant design from the design optimization step of Section 2.4.2. The objective is to maximize the net electricity production while satisfying the heat demand of the DH system. So next to the varying environment conditions, also the fluctuating heat demand and operating temperatures of the DH system cause off-design operation of the CHP plant. The off-design optimization model thus becomes:

$$
\begin{array}{ll}
\text { max. } & \dot{P}_{\text {net }} \\
\text { s.t. } & \Delta T_{\text {sup }}^{\text {min }} \leq T_{6}-T_{4} \leq T_{\text {upper }}-T_{\text {env }} \\
& 10^{\circ} C \leq T_{4}-T_{1} \leq 2\left(T_{\text {upper }}-T_{e n v}\right) \\
& T_{b, i n j}^{\text {min }} \leq T_{b, \text { inj }} \leq T_{b, \text { prod }} \\
& \Delta T_{\text {min }} \leq \Delta T_{\text {pinch }} \\
& \dot{m}_{w f}^{O}=\frac{\dot{m}_{w f}^{D}}{\rho_{6}^{D} c_{6}^{D}} \\
\rho_{6}^{O} c_{6}^{O} & \dot{Q}_{C H P}=\dot{Q}_{D H} \\
& A_{E E S}^{O}=A_{E E S}^{D} \\
& A_{R E C U P}^{O}=A_{R E C U P}^{D} \\
& L_{A C C}^{O}=L_{A C C}^{D} \\
& A_{D H s y s t e m}^{O}=A_{D H \text { system }}^{D} \\
& A_{D H \text { system } 2}^{O}=A_{D H \text { system } 2}^{D} \\
& A_{E C O, H B 4}^{O}=A_{E C O, H B 4}^{D}
\end{array}
$$

The design variables (related to the design of the heat exchangers and the air-cooled condenser) have been fixed in the design optimization step, so only operating variables remain in the off-design optimization model. The first four constraints are set to allow a proper cycle calculation. The symbols follow the same nomenclature as in Figures 1 and 2. $T_{\text {upper }}$ indicates the upper limit for the temperature by REFPROP. The fifth constraint presents single-stage axial turbine operation for choked flow, with $\rho$ and $c$ the density and the speed of sound, respectively. ${ }^{3}$ Furthermore, in

${ }^{3}$ More details on the off-design turbine modeling can be found in [7], in which a similar two-step thermoeconomic 
this work, the heat delivery has priority and the heat demand should always be satisfied by the CHP plant. Since the design is fixed in the design step of the optimization framework, the length of the condenser and the heat transfer areas of the different heat exchangers are fixed. For the HB4 configuration, the economizer heat transfer area is also fixed since the brine flow rate is split before this heat exchanger. So, the physical length of the economizer stays the same. This is in contrast to the other configurations, which allow the point of evaporation to change along the physical length of EES during off-design.

Concerning the verification of the obtained results, it is believed that the optimization results are trustworthy. There are no experimental results available to the authors. Nevertheless, the considered thermoeconomic optimization models are an extension of the thermodynamic optimization models which were developed for a stand-alone electrical power plant and for the four investigated CHP plant configurations of Figure 1. The results of the thermodynamic optimization models have been verified against results in the literature in previous works [36, 37]. The correlations for the heat transfer, pressure drop and turbine modeling are commonly used in the field of ORC modeling and are validated in the literature. In addition, the range of validity for each of the correlations is always respected.

\subsection{High-level optimization model for optimal control}

Once the CHP plant is installed, it is essential to optimize the hourly revenues depending on the real actual electricity and heat prices. Alternatively, the operation might be steered by the heat demand or electricity requirements. The off-design optimization model of Section 2.4 .3 is able to do this, but it is very slow because of the high level of detail. It would therefore take too long to use this model for hourly control purposes. To overcome this, part-load maps are derived from the detailed off-design model results and are used in a high-level control optimization model. This highlevel model is much faster and can be used for control purposes for a certain installed CHP plant installation. The goal is to calculate the optimal amounts of heat and electricity to produce for real price signals and depending on the environment conditions. Note that this high-level model is case-specific since it is derived from the detailed thermoeconomic optimization results for a certain

optimization framework has been presented for a stand-alone binary geothermal power plant. 
The objective is to maximize the revenues $(R)$ during a period of time (the time step is one hour in this paper since hourly data are used). The environment temperature, electricity price and heat price are input parameters to the optimization model. The model is based on the higher-mentioned part-load maps, and the maximal heat which can be produced by the CHP plants depends on the environment conditions: $\dot{Q}_{C H P}^{\max }=f\left(T_{\text {env }}\right)$. The share of this maximal heat production ( $\left.x_{\text {heat }}\right)$ for a given environment temperature is the only variable and is allowed to vary between 0 and 1 . Furthermore, a constraint can be set for the maximal heat delivery (e.g., DH system heat demand) or for the minimal electrical power generation (e.g., to satisfy own power requirements). The high-level control optimization problem can be written as:

$$
\begin{aligned}
\max . & R\left(x_{\text {heat }}\right) \\
\text { s.t. } & \dot{Q}_{C H P}^{m a x} \text { or } \dot{P}_{n e t}^{m i n}
\end{aligned}
$$

\section{Results on the detailed thermoeconomic optimization framework}

The results of the design optimization model are given first, but they do not include off-design performance yet. Second, the off-design performance is calculated for the stand-alone electrical power plant and for the four investigated CHP plant configurations. The actual performance indicators (including off-design behavior) are calculated and the best suited configuration can be indicated.

\subsection{Design optimization results}

In the design optimization step, the stand-alone electrical power plant and the four CHP configurations are optimized for the reference design parameters of Table 1. A standard and a recuperated ORC are considered. Since the use of a recuperator always leads to better economics and a higher NPV, the results are given for the recuperated ORC. Only the NPV, $\dot{P}_{n e t}$, the LCOE, $I_{O R C}$ and $I_{O R C}+I_{D H}$ are given here, but a full analysis of the economic design results (excluding off-design behavior) is given in [14]. 


\begin{tabular}{cc|ccccc} 
& & NPV $[\mathrm{MEUR}]$ & $\dot{P}_{n e t}[\mathrm{MWe}]$ & LCOE $[\mathrm{EUR} / \mathrm{MWh}]$ & $I_{O R C}[\mathrm{MEUR}]$ & $I_{O R C}+I_{D H}[\mathrm{MEUR}]$ \\
\hline 1. & $\mathrm{~S}$ & 4.76 & 3.15 & 49.90 & 11.79 & 12.01 \\
2. & HB4 & 4.58 & 3.13 & 50.02 & 11.79 & 11.92 \\
3. & P & 2.72 & 2.73 & 53.20 & 10.68 & 10.74 \\
4. & PP & 2.58 & 2.70 & 53.50 & 10.54 & 10.69 \\
\hline & ORC & -3.79 & 3.20 & 68.07 & 12.09 & 12.09
\end{tabular}

Table 3: Design optimization results for the four CHP plant configurations (of Figure 1) for a design heat demand of $\dot{Q}_{D H}^{a v}=2.76 \mathrm{MWth}$ and for a stand-alone electrical power plant (ORC), all with recuperated ORC.

It is clear that, considering the design operating point only, the series set-up is the optimal CHP plant configuration for the investigated conditions, closely followed by the HB4 set-up. In the series set-up, the entire brine flow rate goes to the ORC and to the DH system heat exchanger, which is favorable for the small difference between the DH system supply and return temperatures $\left(T_{\text {supply }}-T_{\text {return }}\right)$. In addition, the ORC operation is only little influenced by the DH system in this set-up such that the highest net electrical power generation is achieved.

\subsection{Off-design optimization results}

The off-design performance should be taken into account, since it might have a big impact on the economics. In this work, the off-design optimization results are based on a data reduction technique, which is discussed first. Then, the off-design performance for the stand-alone electrical power plant and for the four CHP plant configurations is presented for the respective optimal designs which were calculated with the design optimization model (a summary of the results was given in Table 3). Based on the off-design results, the actual performance indicators are calculated and the optimal CHP plant can be indicated. Lastly, a note on the accuracy of the data reduction technique is given.

\subsubsection{Data reduction based on the heat duration curve}

The main goal of the off-design optimization procedure is to find the optimal operating conditions which correspond to the maximal net electrical power output for a given environment temperature and heat demand. Instead of performing the optimization for every hour of the reference year, 
a data reduction is performed based on the heat duration curve of the DH system. The number of points is reduced from 8784 (hours in 2016) to 244 , so by a factor of 36 . The original heat curve of Figure 3 has been re-ordered from high to low values to get the heat duration curve. Note that this heat duration curve contains no time-dependency. Every 36 consecutive points on this curve have been averaged to become 1 data point of the reduced curve, which will be used in the off-design optimization procedure to improve the calculation time. The so-called reduced heat duration curve is shown in Figure 4 (in red). Also, the environment temperature and supply and return temperatures have been averaged for 36 consecutive points. The reduced environment temperature curve which corresponds to the reduced heat duration curve is also shown in Figure 4 (black dashdotted line). The CHP plant configurations are designed for the average heat demand, which is indicated by the gray dashed line.

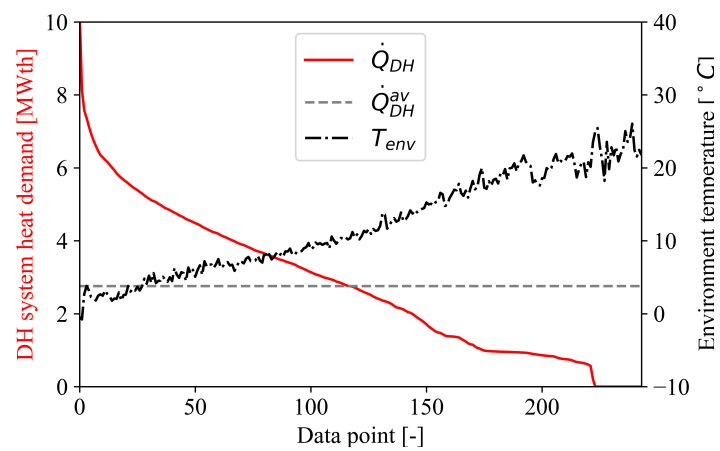

Figure 4: Reduced heat duration curve (red full line) and corresponding environment temperature profile (black dashdotted line) for the 244 data points. The average heat demand is presented by the gray dashed line.

\subsubsection{Optimal operation of the stand-alone electrical power plant}

Figure 5 shows the net electrical power production for the recuperated (black) and the standard (black dotted line) ORC design. The environment temperature is shown in gray and is equal to the black dashdotted line of Figure 4. The electricity production and the environment temperature are negatively correlated, which is expected. Furthermore, it is clear that the recuperated ORC has a higher electricity production. Also the NPV including off-design performance is higher for the recuperated ORC (-3.65MEUR) than for the standard cycle (-4.43MEUR), albeit both are negative, meaning that the stand-alone electrical power plant is not economically attractive $(N P V<0)$. The 


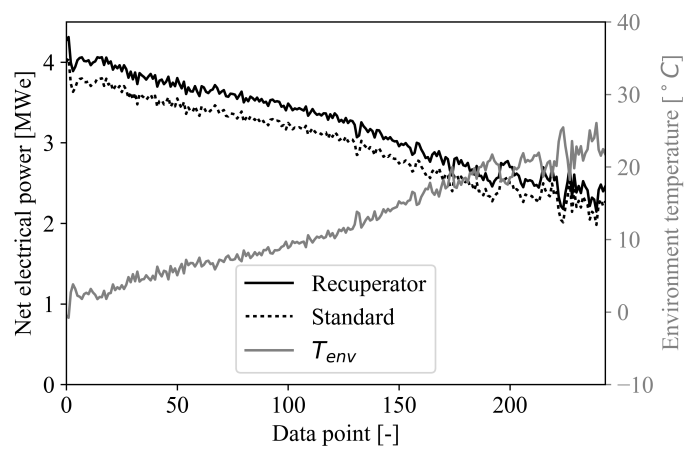

Figure 5: Net electrical power of the standard (black dotted) and the recuperated (black full line) geothermal ORC for the considered data points of Figure 4. The corresponding environment temperature is indicated in gray.

additional heat delivery to a DH system can improve the economics, and that is discussed in the following sections.

\subsubsection{Optimal operation of the combined heat-and-power plants}

Before diving into the discussion of the results, it is important to explain the operational optimization strategy of the CHP plant, based on the optimal economic design point of a particular configuration (parallel, series, preheat-parallel and HB4) as actually built but whereby the offdesign operation invites the operator to switch valves so as to reconfigure the plant and e.g., to allow an originally designed parallel facility to operate in series mode. In the following paragraphs, the optimally designed facilities (parallel, series, preheat-parallel and HB4) will subsequently be used in off-design conditions whereby other operational configurations than the design configuration are allowed and even suggested. It is stressed again that the exercise effectuated here is of economic nature and differs from thermodynamic optimal off-design behavior. As an example, Figure 6 demonstrates the different connections for reconfiguring parallel (blue) and series (green dashed) operation, actually executed via automatically controlled valves (black). For each valve is indicated whether it is closed $(c)$ or open $(o)$ for the considered configuration. All piping needed is given in thin black dotted lines.

Parallel design; off-design operation. The parallel CHP plant as designed in Section 3.1 is not able to satisfy heat demands higher than 4.19MWth. Therefore, the originally-sized DH system heat 


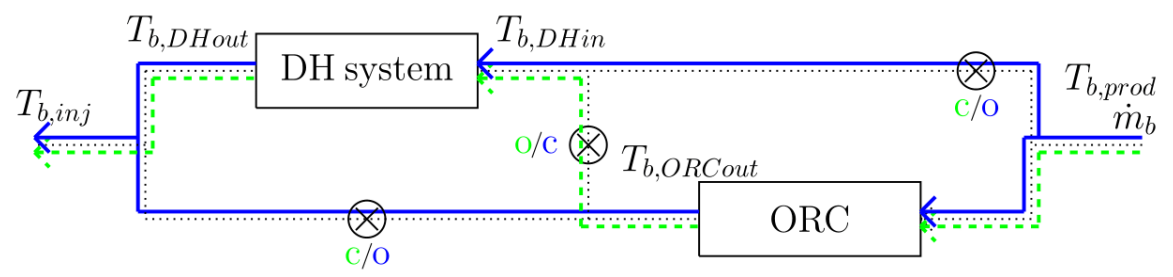

Figure 6: Reconfiguring the parallel (blue) and series (green dashed) connections via automatically controlled valves. The thin dotted lines indicate the piping needed.

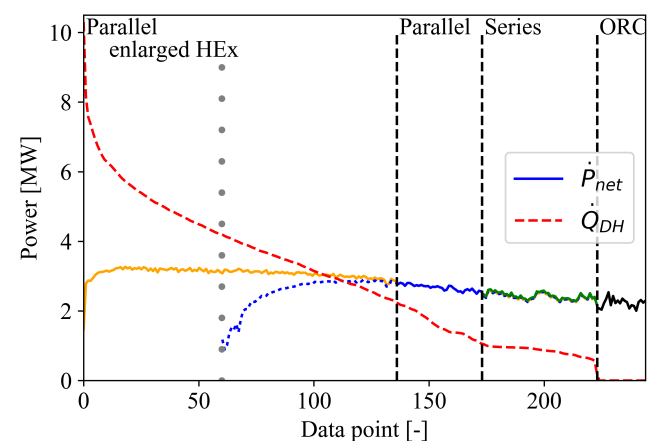

Figure 7: Duration curve for the DH system heat demand (red dashed) and net electrical power of the parallel configuration (orange: enlarged DH system heat exchanger, blue: originally-sized DH system heat exchanger), the series connection (green) and ORC only (black) of the parallel CHP plant design.

exchanger is enlarged from $1.10 \mathrm{~m}$ to $3.65 \mathrm{~m}$, which is sufficient to cover the peak heat demand. The extra cost of the enlarged heat exchanger has been taken into account for the respective economic calculations. Figure 7 shows the off-design electrical and thermal power outputs. The DH system heat demand (red dashed) is always satisfied and the maximal net electrical power output is given, in blue for the original size and in orange for the enlarged heat exchanger. In case of no heat demand, only electricity is produced via the ORC (black). Note that the ORC as designed for the parallel CHP plant is considered in this case.

Note that it is beneficial to use the enlarged heat exchanger, also for heat demands below 4.19MWth. The enlarged heat exchanger allows a larger share of the brine flow rate to go to the ORC such that a higher electricity production is possible than with the originally-size heat exchanger. This can be seen by comparing the orange line (enlarged heat exchanger size) with the blue dotted line 


\footnotetext{
${ }^{4}$ The pinch-point-temperature difference would become too low in this case.
}

(original heat exchanger size). used and the DH bypass valve is always used. flow rate (not only open/close).

The net electricity production of the originally designed parallel CHP plant can be increased slightly by configuring the ORC and the $\mathrm{DH}$ system heat exchanger in series during operation, for heat demands lower than 1.04MWth, which is the maximal heat production of the series connection. The original heat exchanger size of the parallel CHP design is considered for the series connection since no improvements can be made with the enlarged heat exchanger in this case. ${ }^{4}$ Furthermore, two bypass valves are considered for the series connection as shown in Figure 8. The bypass valve over the ORC (called ORC bypass) allows increasing the brine temperature at the DH system heat exchanger inlet and the DH system heat exchanger bypass (called DH bypass) allows part of the brine to bypass the DH system heat exchanger in case of very low heat demands. Note that also part of the brine flow rate can be bypassed (not only open/close operation, but control is also possible). In this case (series connection of the parallel CHP plant design), the ORC bypass is not

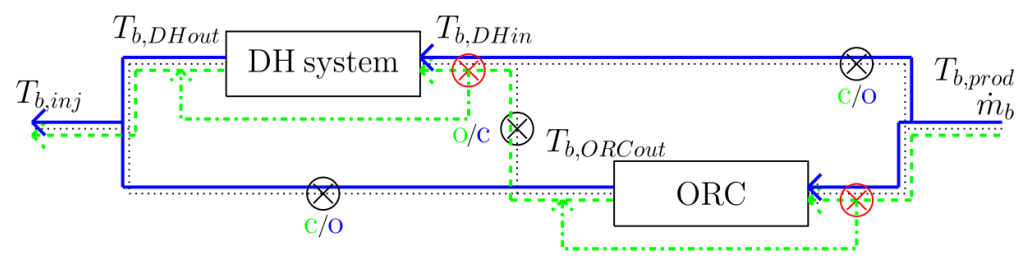

Figure 8: Series configuration (green dashed) of the parallel (blue) CHP plant design, with indication of the two bypass valves (red) which can be used in the series configuration. The bypass valves allow control of the brine mass

Series design; off-design operation. The series CHP plant design of Section 3.1 is able to satisfy heat demands only up to 5.67MWth, even with the use of an ORC bypass valve. The use of an enlarged heat exchanger cannot solve this problem. However, the higher heat demands can be satisfied by connecting the ORC and the DH system heat exchanger of the series CHP plant design in parallel. As will be recalled, every CHP plant configuration has a different optimal design. In this case, the DH system heat transfer area is higher for the series design than for the parallel design, which also explains why the parallel connection with this DH system heat exchanger is able 


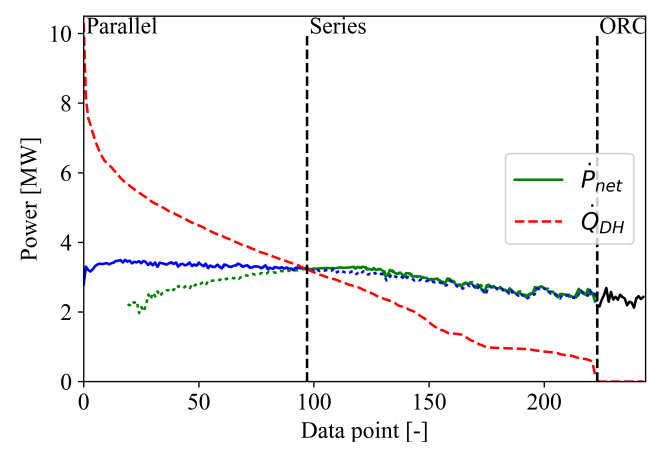

Figure 9: Duration curve for the DH system heat demand (red dashed) and net electrical power of the series (green) and the parallel (blue) connection of the series CHP plant design. The full and the dotted lines indicate the net electrical power output for the data points where the respective CHP connection is optimal, and for the data points where the respective connection is not optimal. Pure ORC operation is indicated in black.

The operational parallel connection (blue) of the series design performs better for heat demands higher than 3.22MWth, and is additionally able to satisfy the peak heat demands. For lower heat demands, the series connection (green) has a slightly higher net electrical power output. For reasons of comparison, the dotted lines indicate the net electrical power output for the series and the parallel connections for the data points where they are not optimal. The series connection cannot satisfy high heat demands, whereas the parallel connection gives good performance over the entire operating range and is highly flexible.

Preheat-parallel design; off-design operation. Figure 10 presents the off-design performance for the preheat-parallel CHP plant design. The DH system heat demand is given in red dashed lines and the net electrical power of the preheat-parallel connection is indicated by the red full line. Observe the very small operating window/low flexibility of the preheat-parallel configuration. Only heat demands between 1.90MWth and 3.31MWth can be satisfied.

Also the results for the parallel configuration of the ORC and the DH system 1 heat exchanger (following the nomenclature of Figure 1) from the preheat-parallel CHP plant design are shown in the blue dashdotted line. Whereas the preheat-parallel connection has a very small operating window, the parallel connection is able to satisfy heat demands up to 7.37MWth. In addition, also 


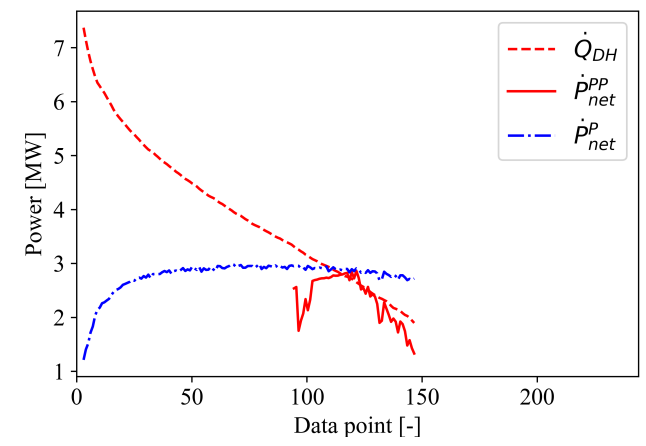

Figure 10: Duration curve for the DH system heat demand (red dashed) and net electrical power for the preheatparallel connection (red), and for the parallel connection (blue dashdotted) of the ORC and the DH system 1 heat exchanger of the preheat-parallel CHP plant design.

the net electricity production of almost the entire operating window for the parallel connection is higher than for the preheat-parallel connection. Based on these results, the preheat-parallel connection is not considered any further.

HB4 design; off-design operation. The HB4 CHP plant design is not able to satisfy all heat demands since it has, like the preheat-parallel CHP plant design, a limited operating regime: $\dot{Q}_{C H P}=$ $2.03-4.23 \mathrm{MWth}$. During operation of the HB4 CHP facility, also two bypass valves can be considered similar to the series connection (see Figure 8); one bypass over the ORC (evaporator and superheater) which is used at high heat demands or for heat demands at a high temperature, and one bypass over the DH system heat exchanger which is used at low heat demands. In order to cover the peak heat demand, the parallel connection of the HB4 CHP design is used with the DH system heat exchanger enlarged by a factor 1.33. For lower heat demands, the series connection is considered.

The left-hand side figure of Figure 11 shows the operating regimes for the HB4 connection (magenta), the parallel connection with enlarged DH system heat exchanger (orange), the parallel connection with originally-sized DH system heat exchanger (blue), the series connection (green) and the stand-alone electrical power plant (black). The maximal net electrical power production is included on the right-hand side. The HB4 connection is optimal for a significant range of data points, but the difference with the parallel configuration is very small. Note the wide operating 


\begin{tabular}{cc|ccc} 
& & NPV $[\mathrm{MEUR}]$ & $\dot{P}_{\text {net }}^{\text {av }}[\mathrm{MWe}]$ & $\mathrm{LCOE}[\mathrm{EUR} / \mathrm{MWh}]$ \\
\hline 1. & HB4 & 3.58 & 3.02 & 51.92 \\
2. & series & 3.46 & 3.02 & 52.17 \\
3. & parallel & 3.34 & 2.81 & 51.90 \\
\hline & ORC & -3.65 & 3.22 & 67.74
\end{tabular}

Table 4: Summary of the results for the CHP plant configurations with recuperated ORC implementation and accounting for off-design performance and the optimal CHP connection.

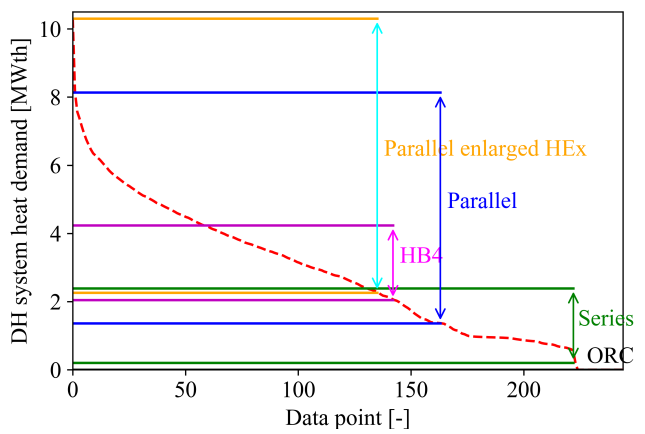

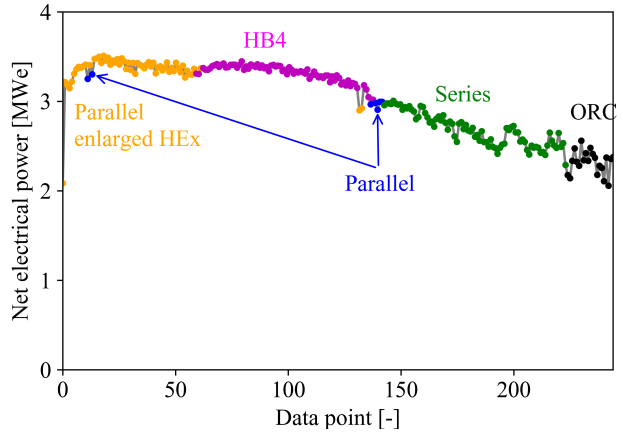

Figure 11: Left: Duration curve for the DH system heat demand (red dashed) and operating windows for the parallel configuration with enlarged DH system heat exchanger (orange), the parallel configuration with original DH system heat exchanger size (blue), the HB4 configuration (magenta), the series configuration (green) and the stand-alone electrical power plant (black) of the HB4 CHP plant design. Right: Maximal net electrical power during off-design operation for the optimal CHP configuration of the HB4 CHP plant design. The main optimal CHP configuration per range of data points is mentioned.

Summary. Table 4 summarizes the off-design results for the different CHP plant designs (but with the optimal connections during operation) and for the stand-alone electrical power plant. The preheat-parallel configuration is not included because it is outperformed by the other configurations. All the mentioned CHP plants are able to satisfy the DH system heat demand.

Note that the NPV values for the HB4 and the series CHP are lower than in Table 3, where off- 
design behavior was not included. This is because the real average net electrical power production is lower than their respective design values. However, for the parallel CHP plant, the NPV value and the average net electrical power output are higher than in Table 3 due to the use of the enlarged DH system heat exchanger for satisfying the peak heat demand (and, with a smaller effect, by using the series connection at lower heat demands).

The HB4 configuration has the highest NPV but considering all four connections during off-design operation is very complex. Therefore, the series design is preferred and the corresponding NPV is only 0.12MEUR lower. The series CHP set-up is much easier, and only the series and parallel connections are used during operation. Note that the LCOE does not follow the same trend as the NPV and $\dot{P}_{n e t}^{a v}$. The revenues from selling heat are included in the LCOE (see Eq. (2)) and the series CHP has the highest electricity production but also the highest investment costs. In this case, this results also in the highest LCOE which means that a slightly higher electricity price is needed to break even at the end of the plant lifetime. However, the LCOE is lower than for the stand-alone electrical power plant.

\subsubsection{Optimal combined heat-and-power plant characteristics}

The series CHP plant was already indicated as the best configuration and the optimal design is given in Table 5. The series and parallel configurations are considered during operation and the optimal connection of the series CHP plant design on an hourly basis (series or parallel) is given in Figure 12. The green, blue and black dots indicate that the series connection (at low heat demands), the parallel configuration (at high heat demands) or the electricity production only mode is optimal, respectively.

Furthermore, this optimal CHP plant has a payback time of 24 years, including well costs, and 8 years excluding the well costs. The avoided $\mathrm{CO}_{2}$ emissions are 14702 ton/year compared to separate heat and electricity production from natural gas. This is based on the following formula:

$$
\text { avoided } \mathrm{CO}_{2}=\left(\frac{\dot{P}_{n e t}^{a v}}{\eta_{C C G T}}+\frac{\dot{Q}_{C H P}^{a v}}{\eta_{b o i l e r}}\right) 8760 C
$$

8

with $\mathrm{C}=200 \mathrm{~kg}-\mathrm{CO}_{2} / \mathrm{MWh}$ the specific carbon dioxide emission factor for natural gas [38], and $\eta_{C C G T}=55 \%$ and $\eta_{b o i l e r}=95 \%$ the efficiencies for a combined cycle gas turbine (electricity production) and a condensing boiler (heating), respectively. 


\begin{tabular}{c|ccc|c|c} 
variable & EES & RECUP & DH SYSTEM & variable & ACC \\
\hline$D_{\text {shell }}[\mathrm{m}]$ & 0.76 & 0.96 & 0.58 & $H_{\text {fin }}[\mathrm{mm}]$ & 23.75 \\
$D_{\text {tube }}[\mathrm{mm}]$ & 6.02 & 5.81 & 8.01 & $S_{\text {fin }}[\mathrm{mm}]$ & 3.04 \\
$p_{\text {tube }}[\mathrm{mm}]$ & 7.22 & 8.89 & 9.61 & $n_{\text {tube }}$ & 1006 \\
$B_{c}[\mathrm{~m}]$ & 0.19 & 0.24 & 0.14 & & \\
$L_{b c}[\mathrm{~m}]$ & 2.94 & 5.00 & 1.20 & &
\end{tabular}

Table 5: Optimal design of the economizer, evaporator, superheater (called $E E S$ ), the recuperator (RECUP), the $D H$ system heat exchanger and the air-cooled condenser $(A C C)$ of the series CHP plant.

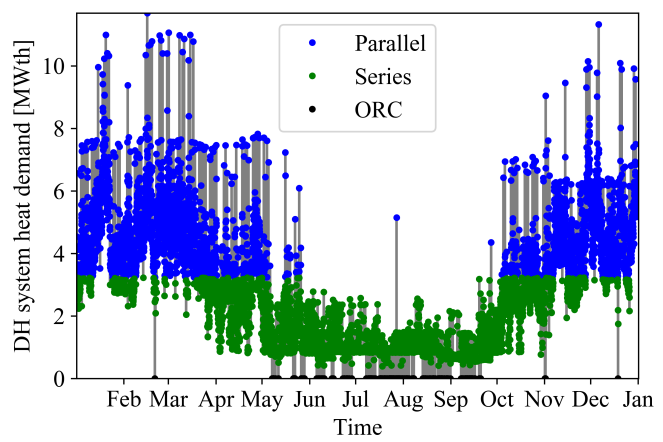

Figure 12: Hourly optimal series (green dot, at low heat demands) or parallel (blue dot, at high heat demands) connection of the series CHP plant design during operation. The black dots indicate pure ORC operation (no heat production). The feasibility map for the series CHP design with optimal off-design connections (series/parallel) is presented in Figure 13. Steps of 30EUR/MWh are considered for the electricity price and steps of $25 \mathrm{EUR} / \mathrm{MWh}$ for the heat price. For the reference parameter values $p_{e l}=60 E U R / M W h$ and $p_{\text {heat }}=25 E U R / M W h, N P V=3.46 M E U R$. The NPV increases linearly with the electricity and heat prices, and is very sensitive to changes in prices. In most cases, and also for the considered reference values for $p_{e l}$ and $p_{h e a t}$, the recuperated ORC leads to better economics. Only for $p_{e l}<$ 39.04EUR/MWh, the standard ORC, having lower investment costs, should be implemented. This value is independent of $p_{\text {heat }}$. 


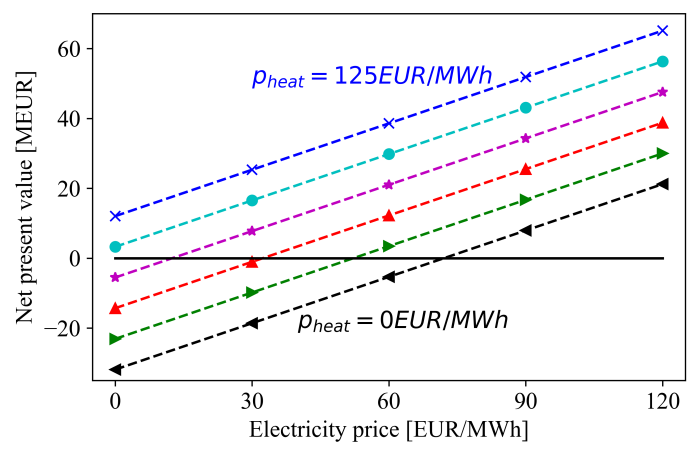

Figure 13: Feasibility map of the series CHP plant design and considering the optimal series/parallel configuration during operation. Steps of 25EUR/MWh are considered for the heat price $\left(p_{\text {heat }}\right)$.

\subsubsection{Note on the data reduction accuracy}

The data reduction (as discussed in Section 3.2.1) improves the calculation time of the off-design optimization model by a factor 36 but introduces some inaccuracies at the same time. A full comparison of the results for the reduced number of data points with a complete hourly simulation for the year 2016 would require more than 10 days of calculation time $(\approx 100 \mathrm{~s} /$ data point). Therefore, four representative blocks of consecutive points on the heat duration curve are introduced. The representative blocks are hours $0-167,2196-2363,4392-4559$, and $6588-6755$.

First, the results are shown for the recuperated stand-alone electrical power plant. On the left-hand side of Figure 14, the real net electrical power output (dashed lines) and the net electrical power output of the reduced data points (full lines) are shown for the four representative blocks. Recall that the electricity production depends on the environment temperature. The right-hand side figure shows the respective real (dashed lines) and reduced (full lines) values for the environment temperature. The reduced values for the environment temperature correspond to the black dashdotted line of Figure 4.

The total and average revenues $\left(R_{\text {tot }}\right.$ and $\left.R_{\text {hour }}\right)$, the average net electricity production and the errors on the total revenues and on the hourly net electrical power output between using the reduced number of data points and the real hourly data for each of the representative blocks are given in Table 6. Since the electricity production is the only product, the relative errors (in $\%$ ) on the hourly electricity production are equal to the relative errors on the hourly revenues 

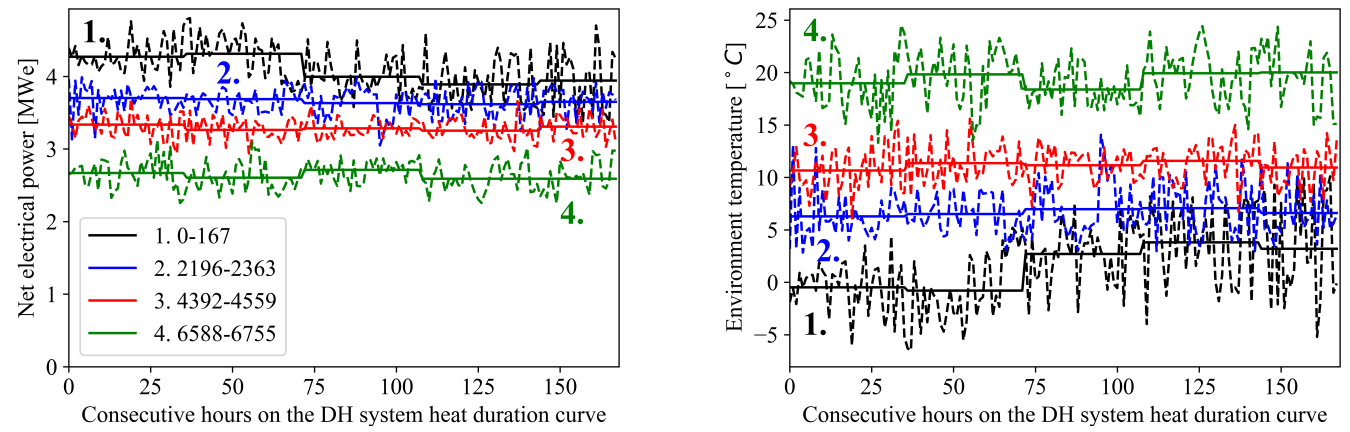

Figure 14: Left: Real net electrical power output (dashed lines) and results for the reduced number of data points (full lines) for the recuperated stand-alone electrical power plant, and for the four representative blocks of consecutive hours on the DH system heat duration curve (black: hours 0-167, blue: hours 2196-2363, red: hours 4392-4559 and green: hours 6588-6755). Right: corresponding real and reduced values for the environment temperature of the representative blocks.

from selling this electricity. However the absolute numbers (in EUR) depend on the electricity price. The deviations of the electricity production are caused by the environment temperature fluctuations and are below $19.12 \%$ on an hourly basis. The average errors on the hourly electricity production/hourly revenues for the four representative blocks are between $0.11 \%$ and $0.56 \%$, which is of satisfying accuracy.

Also the same time blocks are studied for the series CHP plant. Figure 15 shows the heat production and the net electrical power production for the reduced data points (full lines) and for the real hourly data (dashed lines) for the four representative blocks. For the first two blocks, the parallel connection is optimal, for the latter two blocks the series connection is optimal.

From Figure 15, it follows that the largest errors on the heat production are made in the first block (block $0-167$, black). For the first data point, the use of the reduced number of data points results in an under-prediction of the real heat production by $11.86 \%$. For the last data point of this first block (hour 167), the error is $13.56 \%$. However, the average values are always between $-0.03 \%$ and $0.06 \%$, which is of good accuracy. The errors on the net electrical power production show higher variability due to the fluctuating environment conditions (which were given on the righthand side figure of Figure 14). The largest under- and over-predictions of the real net electrical power output are $-15.72 \%$ and $20.53 \%$ for the investigated blocks of representative hours. However, 


\begin{tabular}{|c|c|c|c|c|c|c|c|}
\hline data block & $\begin{array}{l}R_{t o t} \\
{[\mathrm{EUR}]}\end{array}$ & $\begin{array}{l}\Delta R_{t o t} \\
{[\%]}\end{array}$ & $\begin{array}{l}R_{\text {hour }}^{a v} \\
{[\text { EUR] }}\end{array}$ & $\begin{array}{l}\dot{P}_{n e t}^{a v} \\
{[\mathrm{MWe}]}\end{array}$ & $\begin{array}{l}\Delta R_{\text {hour }}^{\min } \\
{[\%]} \\
\Delta \dot{P}_{\text {net }}^{\min } \\
{[\%]}\end{array}$ & $\begin{array}{l}\Delta R_{\text {hour }}^{a v} \\
{[\%]} \\
\Delta \dot{P}_{\text {net }}^{a v} \\
{[\%]}\end{array}$ & $\begin{array}{l}\Delta R_{\text {hour }}^{\max } \\
{[\%]} \\
\Delta \dot{P}_{\text {net }}^{\max } \\
{[\%]}\end{array}$ \\
\hline $0-167$ & 41231 & 0.03 & 245.43 & 4.09 & -16.14 & 0.56 & 17.02 \\
\hline 2196-2363 & 36866 & 0.01 & 219.44 & 3.66 & -9.01 & 0.30 & 19.12 \\
\hline $4392-4559$ & 33164 & -0.10 & 197.40 & 3.29 & -11.11 & 0.11 & 13.42 \\
\hline 6588-6755 & 26649 & -0.29 & 158.62 & 2.64 & -15.79 & 0.21 & 18.35 \\
\hline
\end{tabular}

Table 6: Total revenues, the error on the total revenues, the average hourly revenues, the average electricity production and the minimum, average and maximum errors on the hourly revenues for the four representative blocks of consecutive hours on the DH system heat duration curve (hours 0-167, hours 2196-2363, hours 4392-4559 and hours 6588-6755) for the stand-alone electrical power plant. To recap, $p_{e l}=60 E U R / M W h$.
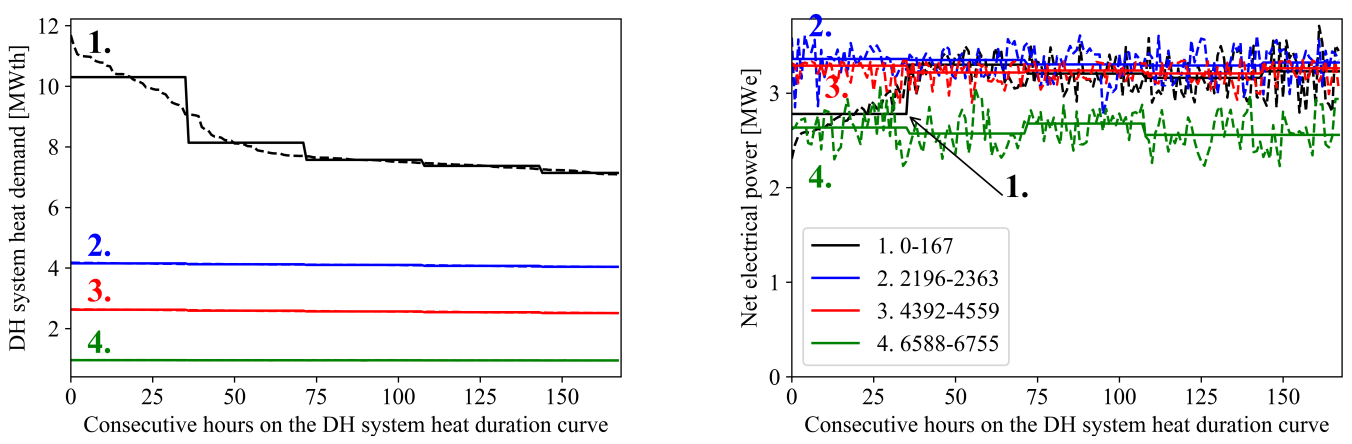

Figure 15: Left: Real heat production (dashed lines) and results for the reduced number of data points (full lines) for the series CHP plant, and for the four representative blocks of consecutive hours on the DH system heat duration curve (black: hours 0-167, blue: hours 2196-2363, red: hours 4392-4559 and green: hours 6588-6755). Right: corresponding real and reduced values of the net electrical power output. 


\begin{tabular}{l|ll|ll|lll} 
data block & $R_{\text {tot }}$ & $\Delta R_{\text {tot }}$ & $R_{\text {hour }}^{a v}$ & $x_{\text {heat }}^{R_{\text {tot }}}$ & $\Delta R_{\text {hour }}^{\text {min }}$ & $\Delta R_{\text {hour }}^{\text {av }}$ & $\Delta R_{\text {hour }}^{\text {max }}$ \\
& {$[\mathrm{EUR}]$} & {$[\%]$} & {$[\mathrm{EUR}]$} & {$[\%]$} & {$[\%]$} & {$[\%]$} & {$[\%]$} \\
\hline $0-167$ & 65697 & 0.24 & 391.05 & 52.28 & -7.03 & 0.33 & 7.71 \\
$2196-2363$ & 50734 & 0.02 & 301.99 & 33.95 & -6.04 & 0.14 & 11.72 \\
$4392-4559$ & 43202 & 0.61 & 257.16 & 24.99 & -3.37 & 0.68 & 9.93 \\
$6588-6755$ & 30311 & -0.25 & 180.42 & 13.19 & -13.91 & 0.12 & 15.48
\end{tabular}

Table 7: Total revenues and error on the total revenues by using the reduced number of data points, the average hourly revenues, the share of the revenues from heat in the total revenues and the minimum, average and maximum relative errors on the total hourly revenues for the four representative blocks of consecutive hours on the DH system heat duration curve (hours 0-167, hours 2196-2363, hours 4392-4559 and hours 6588-6755) for the series CHP plant. To recap, $p_{e l}=60 E U R / M W h$ and $p_{\text {heat }}=25 E U R / M W h$.

the average errors on the net electrical power production are always between $0.20 \%$ and $0.98 \%$, which is of satisfying accuracy. The results based on the reduced number of data points slightly over-predict the electricity production. Note that, as for the stand-alone electrical power plant, the relative errors on the net electrical power production and the respective revenues from selling this electricity, and on the heat production and the respective revenues from selling heat do not depend on the prices for heat and electricity.

Table 7 presents the total and average hourly revenues, the percentage of the total revenues from selling heat $\left(x_{\text {heat }}^{R_{\text {tot }}}\right)$, the errors on the total revenues and on the hourly revenues between using the reduced number of data points and the real hourly data for each of the representative blocks. Because of the two products, the revenues and the errors on the revenues do depend on the prices for heat and electricity. The deviations on the hourly revenues can be as high as $15.48 \%$. However, the errors on the total revenues are always way below $0.61 \%$. This is of satisfying accuracy. To be clear, the goal of the results from the two-step optimization model is to choose the optimal configuration for implementation (and to be built), taking into account its performance during off-design. Of course, for hourly control issues, a quick and accurate model based on hourly data is required. This is the topic of the next section. 


\section{Results on the high-level control optimization model}

Once the CHP plant is installed, the operation can be steered by the heat demand or electricity requirements, but also by the price signals. To be able to calculate the optimal amounts of heat and electricity as well as the optimal connection, the part-load operation of the CHP plant should be known. Therefore, a discretization procedure and polynomial fits for the part-load operation based on the detailed optimization results are discussed first. These part-load maps are used in the highlevel model of Section 2.5 and the results are verified against the detailed off-design optimization results. Finally, the high-level model is run for different scenarios.

\subsection{Discretization and polynomial fits for the part-load operation of the series combined heat-and- power plant design}

Figure 16 shows the maximum heat production limit for the parallel (blue X) and the series connection (green dot) of the series CHP plant design, and the maximum electrical power production limit (black + ), depending on the environment temperature. On the right-hand side, also the electricity production corresponding to the maximal heat productions of the series (green dot) and the parallel (blue X) connections are shown. The maximal electricity and heat production of the series and the parallel connections as a function of the environment temperature are approximated with spline functions (red dashed lines), with good accuracy.

Furthermore, to be able to calculate off-design operation points, the amount of heat versus electricity production should be known (the so-called part-load maps). The real environment temperature varies between $-6.5^{\circ} \mathrm{C}$ and $35.5^{\circ} \mathrm{C}$ over the year. A discretization with $1^{\circ} \mathrm{C}$ steps has been considered for the parallel CHP; however, the series connection is only operational from $T_{\text {env }}=-3.5^{\circ} \mathrm{C}$ to $35.5^{\circ} \mathrm{C} .^{5}$ The detailed off-design optimization model of Section 3.2 has been run for a fixed heat demand constraint of $10 \%, 20 \%, \ldots 90 \%$ of the maximum heat production for the series and the parallel connections to calculate the corresponding off-design net electricity production. The discretization for the heat production and for the environment temperature are also shown on the left-hand side of Figure 16.

\footnotetext{
${ }^{5}$ For lower environment temperatures and corresponding high supply and return temperatures of the DH system, the series CHP is not able to operate.
} 

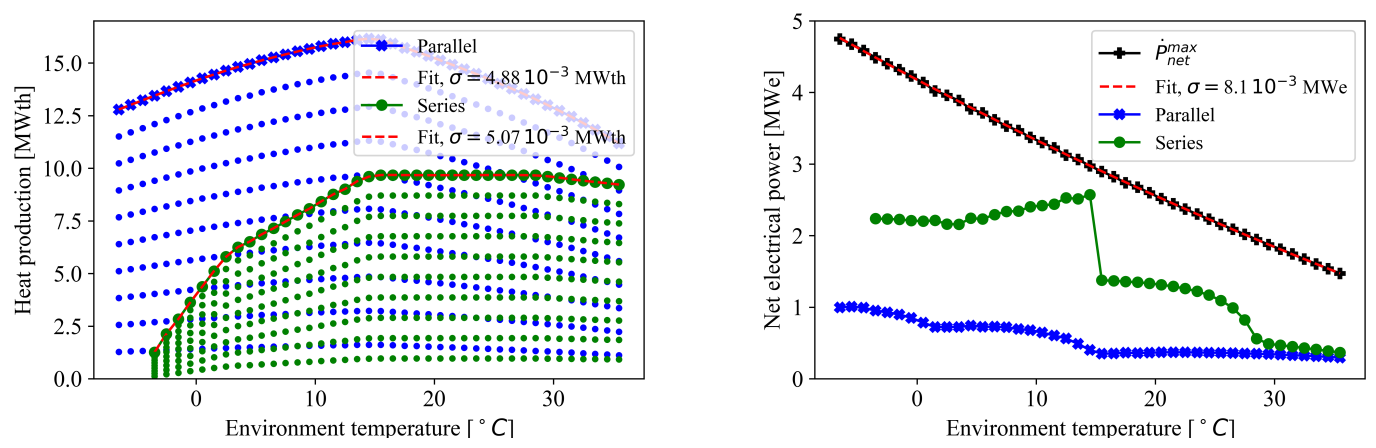

Figure 16: Left: Maximum heat production of the parallel (blue X) and the series (green dot) connection of the series CHP plant design as a function of the environment temperature. The $10 \%$ intervals of the maximal heat production are additionally indicated and used for the polynomial fits. Right: Corresponding net electrical power output to the maximal heat production of the series and the parallel connection and the maximal net electrical power output $($ black + ) in case of no heat delivery.

The high-level optimization model is based on a first-order polynomial fit for the heat production and a tenth order polynomial fit for the net electrical power production as a function of $x_{\text {heat }}{ }^{6}$ $x_{\text {heat }}$ is the share of the maximal heat production. For each discretized value of $T_{\text {env }}$, a different polynomial fit is obtained:

$$
\begin{aligned}
\left.\dot{P}_{n e t}\right|_{T_{e n v}} & =\sum_{i=0}^{10} a_{n} x_{\text {heat }}^{n} \\
\left.\dot{Q}_{C H P}\right|_{T_{\text {env }}} & =b_{0}+b_{1} x_{\text {heat }}
\end{aligned}
$$

${ }^{6}$ It is decided to use a first-order polynomial fit for the heat production since it linearly depends on the share of the maximum heat production for a certain environment temperature. A tenth order polynomial fit is considered over a spline approximation for the net electricity production since it is more accurate. 


\begin{tabular}{|c|c|c|c|c|c|c|c|c|}
\hline data block & $\begin{array}{l}\dot{Q}_{C H P}^{a v} \\
{[\mathrm{MWth}]}\end{array}$ & $\begin{array}{l}\Delta \dot{Q}_{C H P}^{\min } \\
{[\%]}\end{array}$ & $\begin{array}{l}\Delta \dot{Q}_{C H P}^{a v} \\
{[\%]}\end{array}$ & $\begin{array}{l}\Delta \dot{Q}_{C H P}^{\max } \\
{[\%]}\end{array}$ & $\begin{array}{l}\dot{P}_{n e t}^{a v} \\
{[\mathrm{MWe}]}\end{array}$ & $\begin{array}{l}\Delta \dot{P}_{n e t}^{\min } \\
{[\%]}\end{array}$ & $\begin{array}{l}\Delta \dot{P}_{n e t}^{a v} \\
{[\%]}\end{array}$ & $\begin{array}{l}\Delta \dot{P}_{n e t}^{\max } \\
{[\%]}\end{array}$ \\
\hline $0-167$ & 8.18 & -0.08 & -0.00 & 0.00 & 3.11 & -0.65 & 0.07 & 1.02 \\
\hline $2196-2363$ & 4.10 & -0.00 & 0.00 & 0.11 & 3.32 & -0.69 & 0.05 & 0.77 \\
\hline $4392-4559$ & 2.57 & -0.23 & 0.00 & 0.21 & 3.21 & -1.14 & -0.11 & 0.71 \\
\hline $6588-6755$ & 0.95 & -0.38 & 0.03 & 0.71 & 2.61 & -0.47 & -0.04 & 0.63 \\
\hline
\end{tabular}

Table 8: Minimum, average and maximum difference between the high-level model results and the results of the detailed off-design optimization model for the heat production and the net electrical power output of the series CHP design, and for the four representative blocks of consecutive hours on the DH system heat duration curve (hours 0-167, hours 2196-2363, hours 4392-4559 and hours 6588-6755).

\subsection{Verification}

Before giving the results for different scenarios, the high-level model is verified against the results of the detailed off-design optimization model of Section 3.2. The same four representative blocks of consecutive points on the heat duration curve are chosen as in Section 3.2.5. For these blocks, the heat demand of the DH system should be satisfied (fixed constraint to the high-level model, as was the case for the off-design optimization model) and the fluctuating environment temperature is taken into account.

Table 8 shows the minimum, the average and the maximum deviation between the high-level model results and the detailed off-design optimization model results. The errors on the hourly heat production are within $0.71 \%$ and the errors on the hourly net electrical power production are all smaller than $1.14 \%$. The average errors on the hourly heat and electricity production are within $0.13 \%$ and $0.11 \%$, respectively, which indicates good accuracy.

Table 9 shows the total revenues, the error on the total revenues, the average hourly revenues, the share of the revenues which is generated by selling heat and the minimum, average and maximum relative errors on the total revenues. The errors on the total revenues for each of the time blocks are below $0.07 \%$. Furthermore, the errors on an hourly basis are between $-0.86 \%$ and $0.55 \%$ and the average errors are within $0.08 \%$. This is of acceptable accuracy for using the high-level model for real-time control issues. This high-level model is much faster than the detailed off-design optimization model and has errors on the revenues within $0.1 \%$. 


\begin{tabular}{l|ll|ll|lll} 
data block & $R_{\text {tot }}$ & $\Delta R_{\text {tot }}$ & $R_{\text {hour }}^{a v}$ & $x_{\text {heat }}^{R_{\text {tot }}}$ & $\Delta R_{\text {hour }}^{\text {min }}$ & $\Delta R_{\text {hour }}^{a v}$ & $\Delta R_{\text {hour }}^{\text {max }}$ \\
& {$[\mathrm{EUR}]$} & {$[\%]$} & {$[\mathrm{EUR}]$} & {$[\%]$} & {$[\%]$} & {$[\%]$} & {$[\%]$} \\
\hline $0-167$ & 65697 & 0.03 & 391.05 & 52.28 & -0.32 & 0.03 & 0.54 \\
$2196-2363$ & 50734 & 0.03 & 301.99 & 33.95 & -0.46 & 0.03 & 0.52 \\
$4392-4559$ & 43202 & -0.07 & 257.16 & 24.99 & -0.86 & -0.08 & 0.53 \\
$6588-6755$ & 30311 & -0.03 & 180.42 & 13.19 & -0.42 & -0.03 & 0.55
\end{tabular}

Table 9: Total hourly revenues and error on the total revenues by using the high-level model, the average hourly revenues, the share of the revenues from heat in the total revenues and the minimum, average and maximum errors on the hourly revenues for the four representative blocks of consecutive hours on the DH system heat duration curve (hours 0-167, hours 2196-2363, hours 4392-4559 and hours 6588-6755). To recap, $p_{e l}=60 E U R / M W h$ and $p_{\text {heat }}=25 E U R / M W h$.

\subsection{Discussion for different scenarios}

Different scenarios are defined in Table 10 based on the parameter values for the electricity price and heat price, and for the maximal heat production and minimal electricity production constraints. The hourly environment temperature profile (black dashdotted line in Figure 3) is assumed for all scenarios. For the electricity prices, either the fixed price at the design value $\left(p_{e l}=60 E U R / M W h\right.$, from Table 1) or the hourly wholesale day-ahead electricity price profile for Belgium in 2016 [17] $\left(p_{e l}^{2016}\right)$ is assumed. For the heat price, also either the fixed design value $\left(p_{\text {heat }}=25 E U R / M W h\right.$, from Table 1) or the monthly-averaged spot prices for gas in the TTF zone in 2016 [39] $\left(p_{\text {heat }}^{2016}\right)$ are assumed. The profiles for the electricity (blue) and heat (red dashed) prices are shown in Figure $17 .^{7}$

Different numbers are used to indicate the parameter values in the different scenarios:

- 0: The fixed design values for the electricity and heat prices are assumed: $p_{e l}^{D}$ and $p_{\text {heat }}^{D}$;

- 1: The electricity price profile $p_{e l}^{2016}$ is used instead of the fixed electricity price $p_{e l}^{D}$;

- 2: The heat price profile $p_{\text {heat }}^{2016}$ is used instead of the fixed heat price $p_{\text {heat }}^{D}$;

\footnotetext{
${ }^{7}$ Note that the electricity and heat price profiles also start on January 1st 2016 7:00, as for the measurement data for the environment temperature and heat demand of Figure 3.
} 


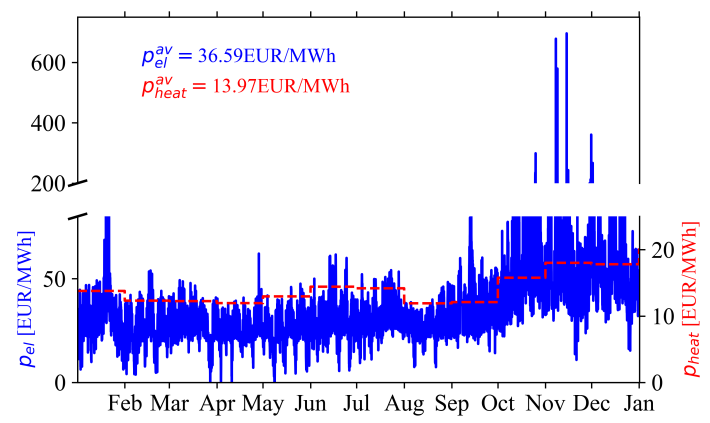

Figure 17: Profiles for the hourly wholesale day-ahead electricity price for Belgium (blue) [17] and for the monthlyaveraged spot price for gas in the TTF zone (red dashed) [39] in 2016. Note the different ordinate scale.

- $\Pi=p_{e l} / p_{\text {heat }}$ indicates that a fixed electricity price, different from the design value, is used. The heat price is always constant at the design value $\left(p_{\text {heat }}^{D}=25 E U R / M W h\right)$.

Furthermore, the constraints are indicated by the letters A and B. No letter means that no constraints are imposed.

- A: The upper limit for the heat production equals the DH system heat demand $\dot{Q}_{D H}$;

- B: The net electrical power production should be higher than 2MWe. 


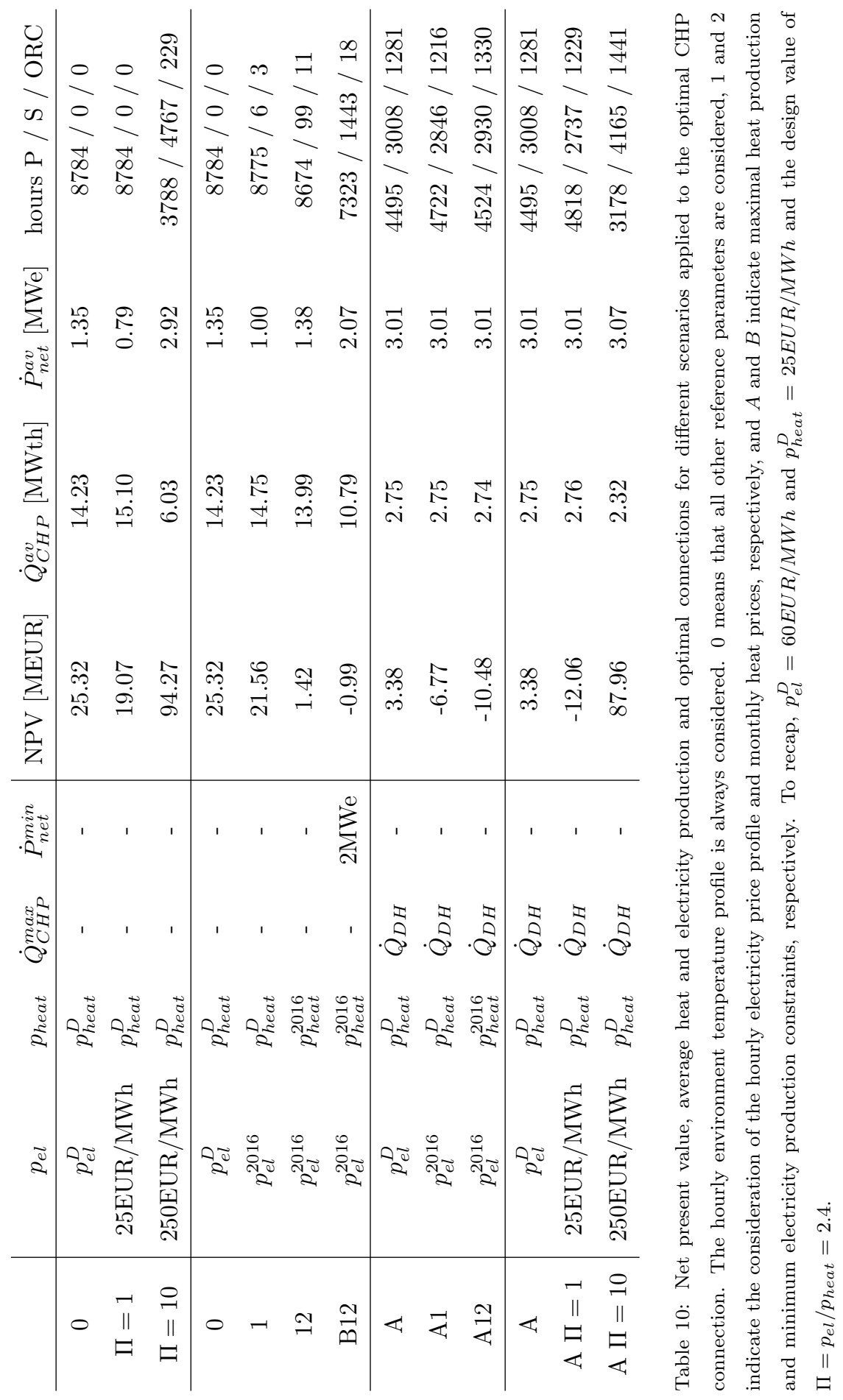


The following conclusions can be made based on the results of Table 10:

1. Influence of the electricity and heat prices:

- In general, it holds that the values of $p_{e l}$ and $p_{\text {heat }}$ determine the real revenues and NPV, but whether the series or the parallel connection is optimal only depends on the ratio $\Pi=p_{e l} / p_{\text {heat }}$.

- The scenario $\Pi=1$ has a lower NPV than the scenario 0 due to the lower electricity price. Furthermore, for lower values of $\Pi$, heat production is promoted and $\dot{Q}_{C H P}^{a v}$ is higher than in the 0 scenario. Correspondingly, $\dot{P}_{n e t}^{a v}$ is lower. The same effect is observed from scenario 0 to scenario 1 , for which the electricity price profile $p_{e l}^{2016}$ is considered instead of the fixed design value for the electricity price. Since the electricity prices of $p_{e l}^{2016}$ are generally lower than 60EUR/MWh, also here the NPV is lower.

- Higher ratios of $\Pi=p_{e l} / p_{\text {heat }}$ lead to more series and ORC (electricity only) operation, as can be seen from scenario 0 to $\Pi=10$. More revenues from selling electricity can be made and the heat production is decreased. This also holds from scenario 0 to 12 . However, the prices are lower so also the NPV is lower.

2. Influence of the heat production upper constraint (indicated by the letter $A$ ):

- The maximum heat production constraint limits the heat production and results in a higher electricity production. So the parallel operation is limited and the series and ORC connections are used more often (see e.g., from scenario 0 to $A$ ). When no constraints are considered, most revenues are made from selling heat, so the revenues are also significantly decreased for scenario $A$ compared to scenario 0 .

- The effects of the prices are less outspoken in case of a heat production constraint. Consider scenarios $A, A \Pi=1$ and $A \Pi=10$. The lower $\Pi=p_{e l} / p_{\text {heat }}$, the more in favor of the parallel connection (scenarios $A$ to $A \Pi=1$ ). The heat production is increased until the upper constraint is reached (set by $\dot{Q}_{D H}$ ). For higher $\Pi=p_{e l} / p_{\text {heat }}$, the series connection and the stand-alone electrical power plant are more in favor, which can be seen when comparing scenarios $A$ to $A \Pi=10$. The heat production is decreased and the electricity production is increased. 
- The same effect can be seen when going from scenario $A$ to $A 1$. For a lower electricity price, the CHP is less operating in electricity only mode (ORC) and more often in parallel connection. Furthermore, if also the heat price is lowered from scenario $A 1$ to A12, so the ratio of $p_{e l} / p_{\text {heat }}$ increases, the ORC mode is used more often. Still, the parallel connection is used a lot due to the high heat demands of the DH system in winter time (and the high revenues from selling heat at that time).

3. Influence of the minimal electricity production constraint (indicated by the letter $B$ ): Due to this higher electricity requirement, less heat can be produced. Consider the scenario B12 compared to scenario 12. The parallel connection is still used the most, but is operated a lower number of hours due to the electrical power restriction. The series CHP is able to produce more electricity in summer time while producing still some heat. For the highest environment temperatures, the heat production of the CHP connections becomes very low, and it is beneficial to use the ORC only.

\section{Conclusions}

In this work, a two-step optimization framework for the design of four CHP plant configurations fueled by low-temperature geothermal energy has been proposed. The off-design optimization and economic investigation of these configurations has not been done before. Furthermore, detailed thermodynamic correlations for the heat transfer coefficients and for the friction factors have been included, and the off-design results are based on hourly data for the heat profile and for the environment conditions.

In general, the recuperated ORC results in better economics than the standard ORC, except for very low heat and electricity prices. Also, it is important to take the off-design behavior into account. The real net present value (NPV) is generally lower when taking into account the off-design operation, since the real electricity production is mostly lower than its design value. Furthermore, the CHP plant design might not be able to satisfy the peak heat demand. For the parallel CHP plant design, a larger heat exchanger can be used to resolve this issue. And for the other CHP designs, the parallel connection can be used during operation to satisfy the highest heat demands. Moreover, by using different connections during off-design, the performance might be further 


\section{improved.}

For the investigated conditions, the series CHP plant design is optimal and the parallel reconfiguration of the designed ORC and the heat exchanger is used to satisfy the high heat demands (at higher temperatures) of the district heating system. The net present value (including off-design) is 3.46MEUR, which is higher than for the stand-alone electrical power plant $(N P V=-3.65 M E U R)$. So the economics of a geothermal project might be improved by providing heat next to electricity.

Once the CHP plant is installed and the investments are made, it is essential to maximize the revenues during operation. For this control issue, a high-level optimization model has been developed, which allows to optimize the amounts of heat and electricity production driven by the actual heat and electricity prices in real time. Depending on the prices and the environment conditions, the parallel or the series CHP configuration, or the stand-alone electrical power production might result in the highest revenues for that period of time (typically one hour). The high-level model is very fast ( milliseconds) and is based on part-load maps which were calculated from the detailed thermoeconomic optimization model. The results were verified against the results of the detailed thermoeconomic optimization model for four representative time blocks, and the control model was found to be of satisfying accuracy. Furthermore, different scenarios were defined to show the applicability of this high-level control model. Up to the authors' knowledge, this is the first paper which presents a thermoeconomic optimization model (including off-design behavior) for CHP design purposes and a derived high-level optimization model for control purposes.

For future work, it is recommended to consider an additional gas boiler in the installation. That way, the control of the geothermal CHP plant is more flexible, e.g.; the owner can decide to produce more electricity during periods with a high electricity price, and the back-up gas boiler can then be used to produce the contracted heat (if not the entire heat demand) for the district heating system. Additionally, also high-temperature thermal storage might improve the flexibility. 


\section{Acknowledgments}

${ }_{666}$ This project is supported by the VITO $\mathrm{PhD}$ grant number 1510829 . The first author would like to

thank dr. Ben Laenen and the VITO management for making this project possible.

668

669

\section{Nomenclature}

Abbreviations

\begin{tabular}{cc}
\hline symbol & description \\
\hline ACC & air-cooled condenser \\
CHP & combined heat-and-power \\
DH & district heating \\
EES & economizer, evaporator, superheater \\
GWP & global warming potential \\
HB4 & HB4 CHP plant [3] \\
NW & northwest \\
ODP & ozone depletion potential \\
ORC & organic Rankine cycle \\
P & parallel CHP plant \\
PP & preheat-parallel CHP plant \\
RECUP & recuperator \\
S & series CHP plant \\
\hline
\end{tabular}




\begin{tabular}{|c|c|}
\hline symbol & description \\
\hline$A\left[m^{2}\right]$ & heat transfer area \\
\hline$B_{c}[\mathrm{~m}]$ & heat exchanger baffle cut \\
\hline$C[\mathrm{USD}]$ & equipment cost \\
\hline$c[\mathrm{~m} / \mathrm{s}]$ & speed of sound \\
\hline$D_{\text {shell }}[\mathrm{m}]$ & shell inner diameter \\
\hline$D_{\text {tube }}[\mathrm{m}]$ & tube outer diameter \\
\hline$d_{e l}[\% /$ year $]$ & electricity price increase \\
\hline$d r[\%]$ & discount rate \\
\hline$\dot{E x}[\mathrm{MWth}]$ & flow exergy \\
\hline$e x[\mathrm{~kJ} / \mathrm{kg}]$ & specific flow exergy \\
\hline$H_{\text {fin }}[\mathrm{mm}]$ & ACC fin height \\
\hline$h[\mathrm{~kJ} / \mathrm{kg}]$ & specific enthalpy \\
\hline$I[\mathrm{MEUR}]$ & investment cost \\
\hline$L$ [year] & lifetime \\
\hline$L_{A C C}[\mathrm{~m}]$ & length of ACC leg \\
\hline$L_{b c}[\mathrm{~m}]$ & heat exchanger baffle distance \\
\hline$L C O E[\mathrm{EUR} / \mathrm{MWh}]$ & levelized cost of electricity \\
\hline$\dot{m}[\mathrm{~kg} / \mathrm{s}]$ & mass flow rate \\
\hline$M W[\mathrm{~g} / \mathrm{mole}]$ & molecular weight \\
\hline$N P V[\mathrm{MEUR}]$ & net present value \\
\hline$N[\%]$ & availability factor \\
\hline$n_{\text {tube }}$ & ACC number of tubes \\
\hline$\dot{P}[\mathrm{MWe}]$ & electrical power \\
\hline$p_{e l}[\mathrm{EUR} / \mathrm{MWh}]$ & electricity price \\
\hline$p_{\text {heat }}[\mathrm{EUR} / \mathrm{MWh}]$ & heat price \\
\hline$p_{\text {tube }}[\mathrm{mm}]$ & tube pitch \\
\hline$p[\mathrm{bar}]$ & pressure \\
\hline$q[\mathrm{~kJ} / \mathrm{kg}]$ & specific heat \\
\hline$\dot{Q}[\mathrm{MWth}]$ & heat \\
\hline$R[\mathrm{EUR}]$ & revenues \\
\hline$S_{\text {fin }}[\mathrm{mm}]$ & ACC fin spacing \\
\hline$s[\mathrm{~kJ} / \mathrm{kgK}]$ & specific entropy \\
\hline$T\left[{ }^{\circ} \mathrm{C}\right]$ & temperature \\
\hline$\dot{V}\left[m^{3} / \mathrm{s}\right]$ & 40 volume flow rate \\
\hline$v_{a i r}[\mathrm{~m} / \mathrm{s}]$ & air velocity \\
\hline$w[\mathrm{~kJ} / \mathrm{kg}]$ & specific work \\
\hline$x_{\text {heat }}[\%]$ & share of the maximal heat production \\
\hline$x_{\text {heat }}^{R_{\text {tot }}}[\%]$ & share of total revenues from heat \\
\hline$\Delta$ & difference \\
\hline$\epsilon[\%]$ & heat exchanger efficiency \\
\hline
\end{tabular}




\begin{tabular}{|c|c|}
\hline symbol & description \\
\hline air & air \\
\hline$a v$ & average \\
\hline$B E$ & bare equipment \\
\hline$b$ & brine \\
\hline crit & critical point \\
\hline$D$ & design \\
\hline$e l$ & electrical \\
\hline en & energy \\
\hline env & environment \\
\hline$e x$ & exergy \\
\hline$f$ & ACC fan \\
\hline$g$ & generator \\
\hline in & inlet \\
\hline$i n j$ & injection state \\
\hline$m$ & motor \\
\hline $\max$ & maximum \\
\hline $\min$ & minimum \\
\hline net & net value \\
\hline out & outlet \\
\hline$p$ & pump \\
\hline pinch & pinch-point \\
\hline prod & production state \\
\hline$O$ & off-design \\
\hline return & DH system return \\
\hline$s$ & isentropic \\
\hline sup & degree of superheating \\
\hline supply & DH system supply \\
\hline$t$ & turbine \\
\hline tot & total \\
\hline$t h$ & thermal \\
\hline upper & upper limit by REFPROP \\
\hline$w f$ & working fluid \\
\hline wells & well drillings \\
\hline
\end{tabular}




\section{References}

[1] D. Walraven, B. Laenen, W. D'haeseleer, Economic system optimization of air-cooled organic Rankine cycles powered by low-temperature geothermal heat sources, Energy 80 (2015) 104113.

[2] F. Heberle, D. Brüggemann, Exergy based fluid selection for a geothermal Organic Rankine Cycle for combined heat and power generation, Applied Thermal Engineering 30 (2010) 13261332 .

[3] M. Habka, S. Ajib, Investigation of novel, hybrid, geothermal-energized cogeneration plants based on organic Rankine cycle, Energy 70 (2014) 212-222.

[4] D. Fiaschi, A. Lifshitz, G. Manfrida, D. Tempesti, An innovative ORC power plant layout for heat and power generation from medium- to low-temperature geothermal resources, Energy Conversion and Management 88 (2014) 883-893.

[5] C. Wieland, D. Meinel, S. Eyerer, H. Spliethoff, Innovative CHP concept for ORC and its benefit compared to conventional concepts, Applied Energy 183 (2016) 478-490.

[6] O. A. Oyewunmi, C. J. Kirmse, A. M. Pantaleo, C. N. Markides, Performance of workingfluid mixtures in ORC-CHP systems for different heat-demand segments and heat-recovery temperature levels, Energy Conversion and Management 148 (2017) 1508-1524.

[7] S. Van Erdeweghe, J. Van Bael, B. Laenen, W. D'haeseleer, Design and off-design optimization procedure for low-temperature geothermal organic Rankine cycles, Applied Energy 242 (2019) $716-731$.

[8] M. Usman, M. Imran, Y. Yang, D. H. Lee, B.-S. Park, Thermo-economic comparison of aircooled and cooling tower based Organic Rankine Cycle (ORC) with R245fa and R1233zde as candidate working fluids for different geographical climate conditions, Energy 123 (2017) $353-366$.

[9] D. Hu, S. Li, Y. Zheng, J. Wang, Y. Dai, Preliminary design and off-design performance analysis of an Organic Rankine Cycle for geothermal sources, Energy Conversion and Management 96 (2015) 175-187. 
[10] M. Astolfi, L. N. La Diega, M. Romano, U. Merlo, S. Filippini, E. Macchi, Techno-economic optimization of a geothermal ORC with novel Emeritus heat rejection units in hot climates, Renewable Energy (2019).

[11] D. Budisulistyo, C. S. Wong, S. Krumdieck, Lifetime design strategy for binary geothermal plants considering degradation of geothermal resource productivity, Energy Conversion and Management 132 (2017) 1-13.

[12] S. Lecompte, H. Huisseune, M. van den Broek, S. De Schampheleire, M. De Paepe, Part load based thermo-economic optimization of the Organic Rankine Cycle (ORC) applied to a combined heat and power (CHP) system, Applied Energy 111 (2013) 871-881.

[13] F. Capra, E. Martelli, Numerical optimization of combined heat and power Organic Rankine Cycles Part B: Simultaneous design \& part-load optimization, Energy 90 (2015) 329-343.

[14] S. Van Erdeweghe, J. Van Bael, B. Laenen, W. D'haeseleer, Optimal configuration for a low-temperature geothermal CHP plant based on thermoeconomic optimization, Energy 179 (2019) 323-335.

[15] S. Van Erdeweghe, J. Van Bael, B. Laenen, W. D'haeseleer, Optimal combined heat-and-power plant for a low-temperature geothermal source, Energy 150 (2018) 396-409.

[16] S. Bos, B. Laenen, Development of the first deep geothermal doublet in the Campine Basin of Belgium, European Geologist 43 (2017) 16-20.

[17] ENTSOE, Central collection and publication of electricity generation, transportation and consumption data and information for the pan-European market, 2016. URL: https:// transparency.entsoe.eu/.

[18] European Commission, EU Reference Scenario 2016, 2014. URL: https://ec.europa.eu/ energy/sites/ener/files/documents/ref2016_report_final-web.pdf.

[19] CREG, Prijs van elektriciteit en aardgas in België, in de 3 regio's en in de buurlanden, 2018. URL: https://www.creg.be/sites/default/files/assets/Prices/ BelEnergyPriceCompNL.pdf. 
[20] S. Lemmens, S. Lecompte, Case study of an organic Rankine cycle applied for excess heat recovery: Technical, economic and policy matters, Energy Conversion and Management 138 (2017) 670-685.

[21] U.S. Department of Energy, Geothermal electric technology, 2016. URL: https://www .wbdg. org/resources/geothermal-electric-technology.

[22] Y. Cao, Y. Dai, Comparative analysis on off-design performance of a gas turbine and ORC combined cycle under different operation approaches, Energy Conversion and Management 135 (2017) 84-100.

[23] J. Foray, Energy efficiency considerations in pumps an pump stations, 2014. URL: http://www . energy $\cdot$ wsu . edu/LinkClick . aspx?fileticket=t3ubiA8D8A4\%3D\&tabid=692\&mid=1345.

[24] J. Bredell, D. Kröger, G. Thiart, Numerical investigation of fan performance in a forced draft air-cooled steam condenser, Applied Thermal Engineering 26 (2006) 846-852.

[25] VITO, Heat network VITO/SCK, Technical Report, VITO, Mol, 2016.

[26] Erdwärme Grünwald, Grüner Strom aus Geothermie, 2013. URL: http://www. erdwaerme-gruenwald.de/Startseite/Informationen-Medien/Informationen/ News-Archiv/E1172.htm.

[27] J. Calm, G. Hourahan, Physical, Safety and Environmental Data for Current and Alternative Refrigerants, in: International Congress of Refrigeration, Prague, Czech Republic, 2011. URL: http://www.hourahan. com/wp/wp-content/uploads/2010/08/ 2011-Physical-Safety-and-Environmental-Data2.pdf.

[28] E. Macchi, M. Astolfi, Organic Rankine Cycle (ORC) Power Systems - Technologies and Applications, Elsevier, 2017.

[29] IEA, Technology Roadmap - Geothermal Heat and Power, 2011. URL: https://www.iea.org/newsroomandevents/pressreleases/2011/june/ how-to-achieve-at-least-a-tenfold-increase-in-supply-of-geothermal-power-and-hea . html. 
[30] G. van Rossum, Python Tutorial, Technical Report CS-R9526, Technical Report, Centrum voor Wiskunde en Informatica (CWI), Amsterdam, 1995. URL: http://www python.org.

[31] J. Andersson, A General-Purpose Software Framework for Dynamic Optimization, Phd, Arenberg Doctoral School, KU Leuven, 2013. URL: https://lirias2repo.kuleuven.be/ bitstream/id/243411/.

[32] A. Wächter, L. T. Biegler, On the implementation of an interior-point filter line-search algorithm for large-scale nonlinear programming, Mathematical Programming 106 (2006) 25-57.

[33] E. Lemmon, M. Huber, M. McLinden, REFPROP - Reference Fluid Thermodynamic and Transport Properties. NIST Standard Reference Database 23, 2007.

[34] R. Smith, Chemical Process Design and Integration, John Wiley and Sons, Inc., 2005.

[35] A. Bejan, G. Tsatsaronis, M. Moran, Thermal Design and Optimization, Wiley, New York, 1996.

[36] S. Van Erdeweghe, J. Van Bael, B. Laenen, W. D’haeseleer, Comparison of series/parallel configuration for a low-T geothermal CHP plant, coupled to thermal networks, Renewable Energy 111 (2017) 494-505.

[37] S. Van Erdeweghe, J. Van Bael, B. Laenen, W. D'haeseleer, Optimal Configuration for Low-T Geothermal CHP Plants, in: GRC Transactions, Vol. 41, Salt Lake City, 2017, pp. 2110-2125. URL: https://www.mech.kuleuven.be/en/tme/research/energy_ environment/PublicationsEnergyandenvironment/Journalpapers.

[38] H. Eggleston, L. Buendia, K. Miwa, T. Ngara, K. Tanabe, IPCC Guidelines for National Greenhouse Gas Inventories, Prepared by the National Greenhouse Gas Inventories Programme, Technical Report, IGES, Japan, 2006. URL: https://www.ipcc-nggip.iges.or.jp/public/ 2006gl/index.html.

[39] Elexys, Gas Spot TTF, 2016. URL: https://my.elexys.be/MarketInformation/SpotTtf . aspx. 